\title{
Illustration of microphysical processes in Amazonian deep convective clouds in the gamma phase space: introduction and potential applications
}

\author{
Micael A. Cecchini ${ }^{1,6}$, Luiz A. T. Machado ${ }^{1}$, Manfred Wendisch ${ }^{2}$, Anja Costa $^{3}$, Martina Krämer ${ }^{3}$, \\ Meinrat O. Andreae ${ }^{4,5}$, Armin Afchine ${ }^{3}$, Rachel I. Albrecht ${ }^{6}$, Paulo Artaxo ${ }^{7}$, Stephan Borrmann ${ }^{4,8}$, Daniel Fütterer ${ }^{9}$, \\ Thomas Klimach ${ }^{4}$, Christoph Mahnke ${ }^{4,8}$, Scot T. Martin ${ }^{10}$, Andreas Minikin ${ }^{9,11}$, Sergej Molleker ${ }^{8}$, Lianet H. Pardo ${ }^{1}$, \\ Christopher Pöhlker ${ }^{4}$, Mira L. Pöhlker ${ }^{4}$, Ulrich Pöschl ${ }^{4}$, Daniel Rosenfeld ${ }^{12}$, and Bernadett Weinzierl ${ }^{9,13,14}$ \\ ${ }^{1}$ Centro de Previsão de Tempo e Estudos Climáticos, Instituto Nacional de Pesquisas Espaciais, Cachoeira Paulista, Brazil \\ ${ }^{2}$ Leipziger Institut für Meteorologie (LIM), Universität Leipzig, Stephanstr. 3, 04103 Leipzig, Germany \\ ${ }^{3}$ Forschungszentrum Jülich, Institut für Energie und Klimaforschung (IEK-7), Jülich, Germany \\ ${ }^{4}$ Biogeochemistry, Multiphase Chemistry, and Particle Chemistry Departments, Max Planck Institute for Chemistry, \\ P.O. Box 3060, 55020 Mainz, Germany \\ ${ }^{5}$ Scripps Institution of Oceanography, University of California San Diego, La Jolla, CA 92037, USA \\ ${ }^{6}$ Departamento de Ciências Atmosféricas, Instituto de Astronomia, Geofísica e Ciências Atmosféricas (IAG), \\ Universidade de São Paulo (USP), São Paulo, Brazil \\ ${ }^{7}$ Instituto de Física (IF), Universidade de São Paulo (USP), São Paulo, Brazil \\ ${ }^{8}$ Institut für Physik der Atmosphäre (IPA), Johannes Gutenberg-Universität, Mainz, Germany \\ ${ }^{9}$ Institut für Physik der Atmosphäre, Deutsches Zentrum für Luft- und Raumfahrt (DLR), Oberpfaffenhofen, \\ 82234 Wessling, Germany \\ ${ }^{10}$ School of Engineering and Applied Sciences and Department of Earth and Planetary Sciences, Harvard University, \\ Cambridge, Massachusetts, USA \\ ${ }^{11}$ Flugexperimente, Deutsches Zentrum für Luft- und Raumfahrt (DLR), Oberpfaffenhofen, Germany \\ ${ }^{12}$ Institute of Earth Sciences, The Hebrew University of Jerusalem, Jerusalem, Israel \\ ${ }^{13}$ Faculty of Physics, University of Vienna, Boltzmanngasse 5, 1090 Vienna, Austria \\ ${ }^{14}$ Ludwig-Maximilians-Universität, Meteorologisches Institut, Munich, Germany
}

Correspondence: Micael A. Cecchini (micael.cecchini@gmail.com)

Received: 28 February 2017 - Discussion started: 15 March 2017

Revised: 13 October 2017 - Accepted: 18 October 2017 - Published: 11 December 2017

\begin{abstract}
The behavior of tropical clouds remains a major open scientific question, resulting in poor representation by models. One challenge is to realistically reproduce cloud droplet size distributions (DSDs) and their evolution over time and space. Many applications, not limited to models, use the gamma function to represent DSDs. However, even though the statistical characteristics of the gamma parameters have been widely studied, there is almost no study dedicated to understanding the phase space of this function and the associated physics. This phase space can be defined by the three parameters that define the DSD intercept, shape, and curvature. Gamma phase space may provide a com-
\end{abstract}

mon framework for parameterizations and intercomparisons. Here, we introduce the phase space approach and its characteristics, focusing on warm-phase microphysical cloud properties and the transition to the mixed-phase layer. We show that trajectories in this phase space can represent DSD evolution and can be related to growth processes. Condensational and collisional growth may be interpreted as pseudo-forces that induce displacements in opposite directions within the phase space. The actually observed movements in the phase space are a result of the combination of such pseudo-forces. Additionally, aerosol effects can be evaluated given their significant impact on DSDs. The DSDs associated with liquid 
droplets that favor cloud glaciation can be delimited in the phase space, which can help models to adequately predict the transition to the mixed phase. We also consider possible ways to constrain the DSD in two-moment bulk microphysics schemes, in which the relative dispersion parameter of the DSD can play a significant role. Overall, the gamma phase space approach can be an invaluable tool for studying cloud microphysical evolution and can be readily applied in many scenarios that rely on gamma DSDs.

\section{Introduction}

Tropical deep convective clouds (DCCs) constitute an important source of precipitation (Liu, 2011) and they interact with atmospheric solar and terrestrial radiation, dynamical processes, and the hydrological cycle (Arakawa, 2004). Deep tropical convection is responsible for transporting energy upwards and thus sustaining the Hadley circulation that redistributes heat to higher latitudes (Riehl and Malkus, 1958; Riehl and Simpson, 1979; Fierro et al., 2009, 2012). Therefore, understanding the processes that impact the characteristics of tropical DCCs is crucial in order to comprehend and model the Earth's climate.

The DCCs over the Amazon are of particular interest. Given the relative homogeneity of the surface (as compared to urbanized regions) and the pristine air over undisturbed portions of the rainforest, Amazonian DCCs can have similar properties to maritime systems (Andreae et al., 2004). At the same time, their daily persistence and the considerable latent heat release have a noticeable impact on the South America climate by, for instance, maintaining the Bolivian High, which is a key component of the South American monsoon system (Zhou and Lau, 1998; Vera et al., 2006).

Clouds and aerosol particles interact in a unique way in the Amazon. Low concentrations of natural aerosols derived from the forest are the major source of natural cloud condensation nuclei (CCN) and ice-nucleating particle (INP) populations under undisturbed conditions (Pöschl et al., 2010; Prenni et al., 2009; Pöhlker et al., 2012, 2016). Other sources of aerosol particles over the Amazon include long-range Saharan dust and sea salt transport, biomass burning (either naturally occurring or human-induced), and urban pollution downwind from cities and settlements (Talbot et al., 1988, 1990; Cecchini et al., 2016; Martin et al., 2010; Kuhn et al., 2010).

Human-emitted pollution can significantly alter cloud properties by enhancing $\mathrm{CCN}$ number concentrations $\left(N_{\mathrm{CCN}}\right)$. Since the work of Twomey (1974) analyzing the effects of enhanced $N_{\mathrm{CCN}}$ on cloud albedo, much attention has been given to aerosol-cloud-precipitation interactions. The effects of aerosol particles on warm-phase precipitation formation is fairly well understood, with enhanced $\mathrm{CCN}$ concentrations leading to the formation of more numerous but smaller droplets delaying the onset of rain (Albrecht, 1989; Seifert and Beheng, 2006; van den Heever et al., 2006; Rosenfeld et al., 2008). However, in mixed-phase clouds, the rain suppression by pollution can enhance ice formation, leading to stronger updrafts and convective invigoration (Andreae et al., 2004; Khain et al., 2005; van den Heever et al., 2006; Fan et al., 2007; van den Heever and Cotton, 2007; Lee et al., 2008; Rosenfeld et al., 2008; Koren et al., 2010; Li et al., 2012; Gonçalves et al., 2015). Aerosol effects on clouds have been reviewed by Tao et al. (2012), Rosenfeld et al. (2014), and Fan et al. (2016). By changing cloud properties, aerosol particles have an indirect impact on the thermodynamics of local cloud fields through, for instance, the suppression of cold pools and the enhancement of atmospheric instability (Heiblum et al., 2016b).

Clouds that develop above the freezing level are more difficult to model given the complexity of the processes involving ice particles. One aspect of the aerosol effects on clouds is their ability to alter the way in which ice is formed in the mixed phase of convective clouds. Contact freezing is possibly the dominant process by which the first ice is formed (Cooper, 1974; Young, 1974; Lamb et al., 1981; Hobbs and Rangno, 1985). As pointed out by Lohmann and Hoose (2009), anthropogenic aerosol particles can either enhance or hinder cloud glaciation due to primary aerosol emission (increasing INP concentrations) and aerosol particle coating (decreasing INP effectiveness), respectively. After the initial ice formation, secondary ice generation can be triggered by the release of ice splinters from freezing droplets (Hallett and Mossop, 1974; Huang et al., 2008; Sun et al., 2012; Lawson et al., 2015). Rather big (larger than $23 \mu \mathrm{m}$ ) cloud and drizzle droplets favor secondary ice generation (Mossop, 1978; Saunders and Hosseini, 2001; Heymsfield and Willis, 2014). Consequently, the smaller droplets found in polluted Amazonian clouds (Andreae et al., 2004; Cecchini et al., 2016; Wendisch et al., 2016) may slow down secondary ice generation.

In order to model aerosol effects on clouds and the thermodynamic feedback processes involved, it is crucial to understand their effects on hydrometeor size distributions. The first step is the study of aerosol impacts on liquid droplet size distributions (DSDs) in the cloud's warm phase. Operational models that require fast computations usually adopt a gamma function (Ulbrich, 1983) to parameterize the DSDs:

$N(D)=N_{0} D^{\mu} \exp (-\Lambda D)$,

where $N_{0}\left(\mathrm{~cm}^{-3} \mu \mathrm{m}^{-1}\right), \mu$ (dimensionless), and $\Lambda\left(\mu \mathrm{m}^{-1}\right)$ are the intercept, shape, and curvature parameters, respectively. $N(D)$ is the concentration of droplets per cubic centimeter of air and diameter $(D)$ bin interval. Even though the gamma function is widely adopted in models (Khain et al., 2015), there is almost no study regarding its phase space for checking DSD predictions between parameterization schemes. 
The phase space of cloud micro- and macrophysical properties has received recent attention because of the considerable gain of information accessible using relatively simple analysis tools. Heiblum et al. (2016a, b) studied cumulus fields in a two-dimensional (2-D) phase space consisting of the cloud center of gravity versus water mass. The authors were able to evaluate several processes in this subspace, including the aerosol effect. McFarquhar et al. (2015) studied the gamma phase space for improving ice particle size distribution (PSD) fitting and parameterization. They showed that the inherent uncertainty of gamma fittings results in multiple solutions for a single ice PSD, corresponding to ellipsoids rather than points in the phase space. However, there is no study regarding the representation of warm-phase cloud DSDs in the gamma phase space and its evolution.

For the representation of hydrometeor size distributions in two-moment bulk schemes, one of the three gamma parameters is either fixed or diagnosed based on thermodynamic or DSD properties (Thompson et al., 2004; Milbrandt and Yau, 2005; Formenton et al., 2013a, b). This process may produce artificial trajectories in the phase space by limiting the parameter variability. This study analyzes cloud DSD data collected during the ACRIDICON-CHUVA campaign (Wendisch et al., 2016) in the gamma phase space. ACRIDICON is the acronym for Aerosol, Cloud, Precipitation, and Radiation Interactions and Dynamics of Convective Cloud Systems, while CHUVA stands for Cloud Processes of the Main Precipitation Systems in Brazil: A Contribution to Cloud Resolving Modeling and to the GPM (Global Precipitation Measurement). The gamma phase space and its potential use for understanding cloud processes is introduced and explored. A specific focus is on the aerosol effect on the trajectories in the warm-layer phase space and potential consequences for the mixed-phase formation.

Section 2 describes the instrumentation and methodology. The results are presented in Sect. 3, followed by concluding remarks in Sect. 4.

\section{Methodology}

\subsection{Flight characterization}

During September-October 2014, the German HALO (High Altitude and Long Range Research Aircraft) performed a total of $96 \mathrm{~h}$ of research flights over the Amazon. The 14 flights were part of the ACRIDICON-CHUVA campaign (Machado et al., 2014; Wendisch et al., 2016) that took place in cooperation with the second intensive operation period (IOP2) of the GoAmazon2014/5 experiment (Martin et al., 2016). Here we focus on cloud profiling sections during six flights that occurred in different regions in the Amazon (Fig. 1). The research flights of ACRIDICON-CHUVA were named chronologically from AC07 to AC20; the six flights selected (AC07, AC09, AC12, AC13, AC18, and AC19) accumulated
$16.8 \mathrm{~h}$ of data (in or out of clouds), of which 50 min were inside the lower $6 \mathrm{~km}$ of the clouds. We concentrate primarily on the first $6 \mathrm{~km}$ for the DSD analysis in order to capture both warm-phase characteristics and early mixedlayer formation. There were other flights with cloud penetrations, but they are not considered in this study because of higher aerosol variability below clouds. The flights chosen for analysis presented relatively low aerosol variability, meaning that the clouds probed in the same flight were likely subject to similar aerosol conditions. The time frame of the campaign corresponds to the local dry-to-wet season transition, when biomass burning is active in the southern Amazon (Artaxo et al., 2002; Andreae et al., 2015). For clarity, the flights of interest are renamed in this study according to the region probed. Flight AC19 will be referred as M1 (Maritime 1), flights AC09 and AC18 as RA1 and RA2 (Remote Amazon 1 and Remote Amazon 2, respectively), and flights AC07, AC12, and AC13 as AD1, AD2, and AD3 (Arc of Deforestation 1, Arc of Deforestation 2, and Arc of Deforestation 3 , respectively). Those definitions are listed in Table 1.

The flight paths followed a regular three-stage pattern: (i) sampling of the air below clouds for aerosol characterization, (ii) measurements of DSDs at cloud base, and (iii) sampling of growing convective cloud tops (Braga et al., 2017; Wendisch et al., 2016). The latter step was deployed as follows. After the cloud base penetration, the aircraft performed several penetrations in vertical steps of several hundred meters. In each step, the aircraft penetrated the cloud tops available, thus avoiding precipitation from above. In this way, different clouds can be penetrated in the same altitude level and the vertical steps followed the growing cumuli field overall. Surface and thermodynamic conditions were different for the various flights (see Figs. 1 and 3) with high contrasts in the north-south direction. Logging, agriculture, and livestock activity management involves burning extended vegetated areas in the region, which emits large quantities of particles that serve as CCN in the atmosphere (Artaxo et al., 2002; Roberts et al., 2003). Because of this, this region is known as the "arc of deforestation," and its thermodynamic properties tend toward pasture-like characteristics. The energy partitioning over pasture-like areas is different compared to regions over the rainforest (Fisch et al., 2004), favoring sensible heat flux and higher cloud base heights (see Table 1). Contrasting with the arc of deforestation, the region named Remote Amazon in this study has much lower background aerosol concentrations, producing cleaner clouds. Clouds over the Atlantic Ocean developed under cleaner conditions as compared to the continental counterparts, and also had lower cloud bases (Table 1).

The cloud profiling missions were mostly characterized by cumulus fields, with some developed convection in two flights over the arc of deforestation (Fig. 2d and f). For flight AD1 some precipitation-sized droplets were observed (not shown); the clouds sampled during AD2 and AD3 presented almost no droplets with $D>100 \mu \mathrm{m}$. The precipitation dur- 
Table 1. General characteristics of the cloud profiling missions of interest to this study: condensation nuclei $\left(N_{\mathrm{CN}}\right)$ and $\mathrm{CCN}$ concentrations $\left(N_{\mathrm{CCN}}\right.$, with $S=0.48 \pm 0.033 \%$ ), cloud base and $0{ }^{\circ} \mathrm{C}$ isotherm altitude ( $H_{\text {base }}$ and $H_{0}{ }^{\circ} \mathrm{C}$, respectively), start and end time, and total number of DSDs collected. The data are limited to the lower $6 \mathrm{~km}$ of the clouds. The unit for $N_{\mathrm{CN}}$ and $N_{\mathrm{CCN}}$ is per cubic centimeter and the unit for altitude is meters. Profile start and end are given in local time. The names in the third column have the following meaning: M1 - Maritime 1; RA1 and RA2 - Remote Amazon 1 and Remote Amazon 2; AD1, AD2, and AD3 - Arc of Deforestation 1, Arc of Deforestation 2, and Arc of Deforestation 3.

\begin{tabular}{lllrrrrrrr}
\hline Region & Flight & $\begin{array}{l}\text { Name } \\
\text { this } \\
\text { study })\end{array}$ & $\begin{array}{r}N_{\mathrm{CN}} \\
\left(\mathrm{cm}^{-3}\right)\end{array}$ & $\begin{array}{r}N_{\mathrm{CCN}} \\
\left(\mathrm{cm}^{-3}\right)\end{array}$ & $\begin{array}{r}H_{\text {base }} \\
(\mathrm{m})\end{array}$ & $\begin{array}{r}H_{0}{ }^{\circ} \mathrm{C} \\
(\mathrm{m})\end{array}$ & Start & End & No. of DSDs \\
\hline Atlantic coast & AC19 & M1 & 465 & 119 & 550 & 4651 & $13: 17$ & $14: 57$ & 630 \\
\hline Remote & AC09 & RA1 & 821 & 372 & 1125 & 4823 & $11: 30$ & $14: 21$ & 665 \\
Amazon & AC18 & RA2 & 744 & 408 & 1650 & 4757 & $12: 32$ & $14: 14$ & 397 \\
\hline Arc of deforestation & AC07 & AD1 & 2498 & 1579 & 1850 & 4848 & $13: 49$ & $17: 16$ & 674 \\
& AC12 & AD2 & 3057 & 2017 & 2140 & 4938 & $12: 55$ & $15: 16$ & 381 \\
& AC13 & AD3 & 4093 & 2263 & 2135 & 4865 & $12: 46$ & $15: 36$ & 204 \\
\hline
\end{tabular}

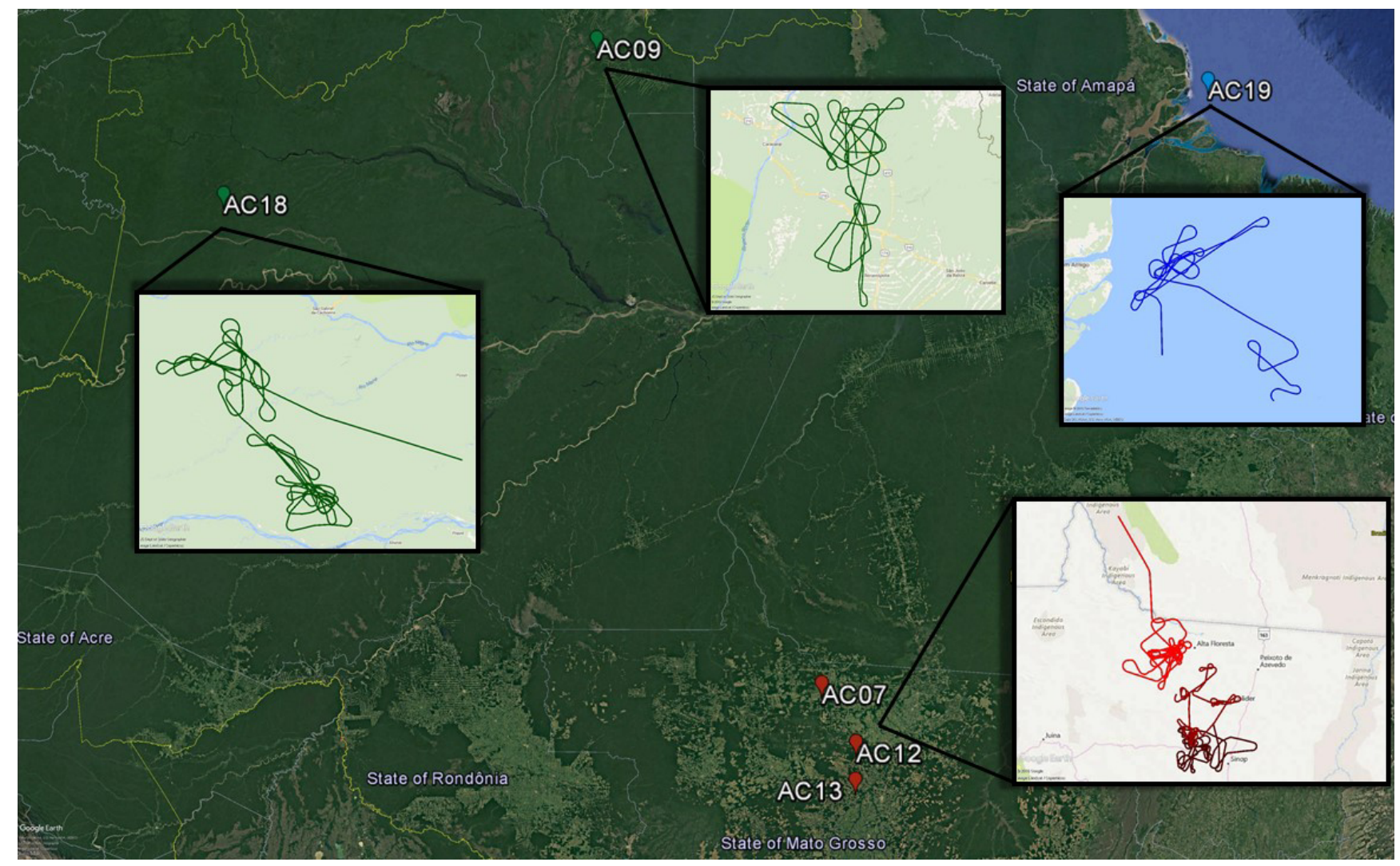

Figure 1. Profile locations and trajectories of interest to this study. The ACRIDICON-CHUVA research flights were labeled chronologically from AC07 to AC20. The labels in the figure reflect the respective flights where the cloud profiling section took place. The colors represent the different regions: green for remote Amazon, blue for near the Atlantic coast, and red for the arc of deforestation (different shades for clarity).

ing $\mathrm{AD} 1$ might be explained by the lower aerosol particle number concentrations compared to flights AD2 and AD3, later start time of the profile, and the presence of deep convection nearby (Table 1 and Fig. 2).

\subsection{Data handling and filtering}

The results to be presented here are based on five sensors carried by HALO. A comprehensive description of the airborne instrumentation introduced below can be found 


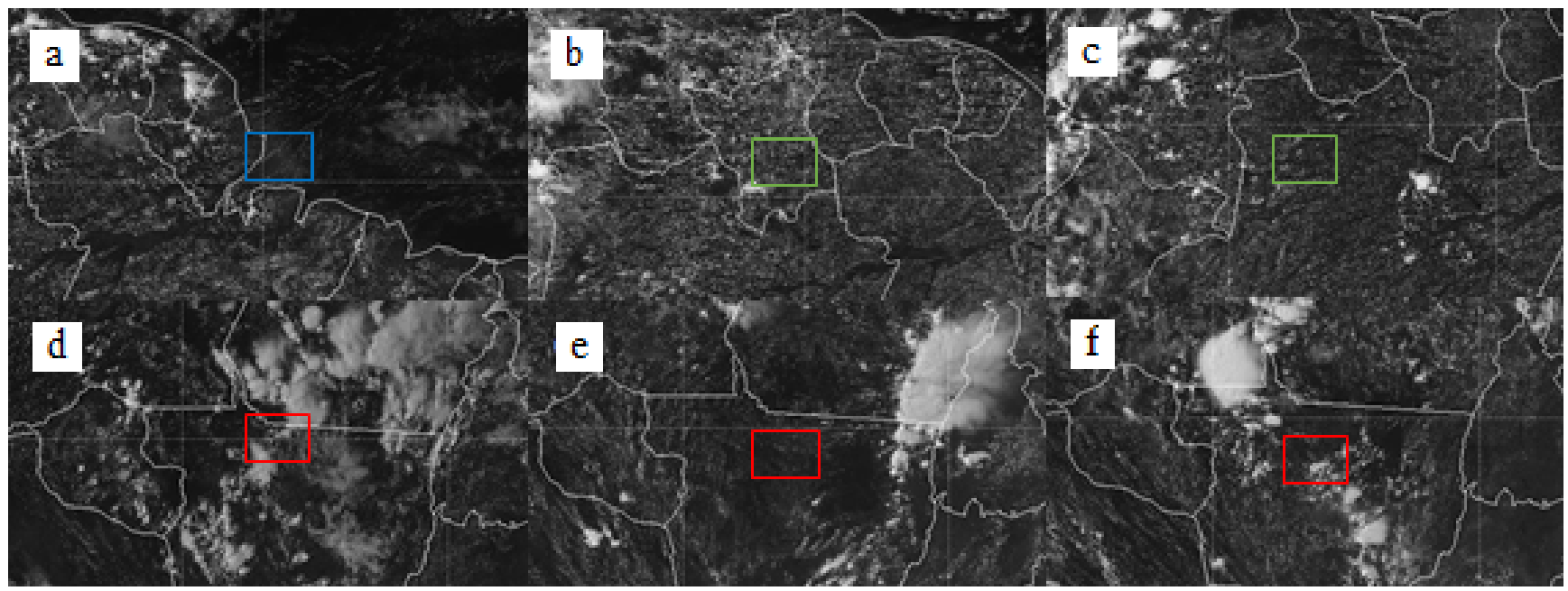

Figure 2. GOES-13 visible images for flights (a) M1, (b) RA1, (c) RA2, (d) AD1, (e) AD2, and (f) AD3. Images are approximately 1 h after the profile start time.

in Wendisch and Brenguier (2013). Aerosol particle number concentrations $\left(N_{\mathrm{CN}}\right)$ were measured using a butanolbased condensation particle counter (CPC). The flow rate was set to $0.6 \mathrm{~L} \mathrm{~min}^{-1}$, with a nominal cutoff particle size of $10 \mathrm{~nm} . N_{\mathrm{CCN}}$ at a given supersaturation $(S$, averaging $0.48 \% \pm 0.033 \%$ for the data used here, with $10 \%$ error) was measured using a cloud condensation nuclei counter (CCN-200; Roberts and Nenes, 2005). This instrument contains two columns and was connected to two different inlet systems for aerosol sampling: the HALO Submicrometer Aerosol Inlet (HASI) for the aerosol particles and the Counterflow Virtual Impactor (CVI) inlet to sample cloud droplets, evaporate the cloud water, and analyze the residual particles. The aerosol measurements reported in this study refer to the HASI inlet.

Cloud DSDs were measured using a cloud droplet probe (CDP; Lance et al., 2010; Molleker et al., 2014) that is part of the cloud combination probe (CCP). The CCP also contained a grayscale cloud imaging probe (CIPgs; Korolev, 2007), but we focus on CDP measurements in which $D<50 \mu \mathrm{m}$. The intent is to focus on cloud droplet growth processes and bringing the analysis closer to modeling scenarios. Additionally, the percentage of data with significant liquid water content (LWC) for $D>50 \mu \mathrm{m}$ is relatively small. The number of data with $\mathrm{LWC}_{D>50}>0.1 \mathrm{~g} \mathrm{~m}^{-3}$ is only $12 \%$ of the number of DSDs with $\mathrm{LWC}_{D<50}>0.1 \mathrm{~g} \mathrm{~m}^{-3}$, meaning that drizzle and precipitation are relatively infrequent in the dataset. This observation combined with the possibility of higher uncertainty (especially on the lower CIPgs bins) when combining two different instruments with distinct measurement principles further justifies the exclusive focus on CDP. The CDP counted and sized the droplets based on their forward scattering characteristics, sorting them into 15 droplet size bins between 3 and $50 \mu \mathrm{m}$. The sample volume had an opti- cal cross section of $0.278 \mathrm{~mm}^{2}( \pm 15 \%)$. Uncertainties in the cross-section area, the sampling volume, and counting statistics were the major sources of uncertainty for the DSD measurements (Weigel et al., 2016). According to Molleker et al. (2014), the CDP uncertainty is about $10 \%$. Additionally, Braga et al. (2017) performed an intercomparison between HALO probes, as well as hot-wire measurements, and concluded that they agree well within instrumental uncertainties. We excluded all cloud DSDs with droplet number concentrations $\left(N_{\mathrm{d}}\right)$ less than $1 \mathrm{~cm}^{-3}$ from further analysis.

The DSDs measured using the CDP were fitted to gamma distributions (Eq. 1) by matching the zeroth, second, and third moments. These moments were chosen in order to favor the study of the DSD properties of interest to this study (i.e., droplet number concentration, LWC, and effective diameter), but they also coincide with the properties usually predicted using bulk microphysics models (zeroth and third moments in two-moment schemes). The complete gamma function is used to be consistent with modeling scenarios, in which the gamma parameters are calculated by

$$
\begin{aligned}
& \mu=\frac{6 G-3+\sqrt{1+8 G}}{2(1-G)} \\
& \Lambda=\frac{(\mu+3) M_{2}}{M_{3}} \\
& N_{0}=\frac{\Lambda^{\mu+1} M_{0}}{\Gamma(\mu+1)},
\end{aligned}
$$

where $M_{p}$ is the $p$ th moment of the DSD. The symbol $G$ is a nondimensional ratio, given as follows: 
$G=\frac{M_{2}^{3}}{M_{3}^{2} M_{0}}$.

The three parameters $N_{0}, \mu$, and $\Lambda$ define the gamma distribution in Eq. (1); they are used to construct the phase space described in the next section. Previous studies comparing the complete and incomplete (or truncated) gamma fits suggest that, while there are differences in the resulting parameters, the relation between them remains similar. The first indication of that comes from the study of Ulbrich (1985) that analyzed the relation between rainfall DSD moments in the empirical form $M_{p}=\alpha M_{q}^{\beta}$, where $p$ and $q$ are the two distinct moment orders and $\alpha$ and $\beta$ are fit parameters. The author notes that $\beta$ is relatively insensitive to DSD truncation, meaning that the relation between the moments remains similar while their overall values change. Brandes et al. (2003) also note that the $\mu-\Lambda$ relation introduced by Zhang et al. (2001) is relatively insensitive to DSD truncation.

In order to confirm that both the complete and incomplete gamma fits result in similar correlations among the DSD parameters, a method similar to the one presented in Vivekanandan et al. (2004) was applied. This method aims to find the incomplete gamma parameters by using an iterative method to adjust $\mu$ and $\Lambda$. Here the moments of order zero, two, and three will be used instead of two, four, and six as in Vivekanandan et al. (2004). The first step is to calculate the ratio $G$ using the incomplete gamma as

$$
\begin{aligned}
& G_{\text {inc }}= \\
& \frac{\left[\gamma\left(\Lambda D_{\max }, \mu+3\right)-\gamma\left(\Lambda D_{\min }, \mu+3\right)\right]^{3}}{\left[\gamma\left(\Lambda D_{\max }, \mu+1\right)-\gamma\left(\Lambda D_{\min }, \mu+1\right)\right]\left[\gamma\left(\Lambda D_{\max }, \mu+4\right)-\gamma\left(\Lambda D_{\min }, \mu+4\right)\right]^{2}},
\end{aligned}
$$

where $\gamma$ is the incomplete gamma function and $\Lambda D_{\min }$ and $\Lambda D_{\max }$ are its integration range. $D_{\min }$ and $D_{\max }$ were calculated from the measured DSDs as the lowest and highest diameter bins associated to drop concentrations higher than $10^{-6} \mathrm{~cm}^{-3}$ (considering both CDP and CIPgs for testing purposes). This ratio is found to be greater than or equal to its counterpart in Eq. (5). Therefore, $\mu$ and $\Lambda$ should be lowered until $G_{\text {inc }}$ is sufficiently close to $G$ (the threshold of 0.001 is used here). For that purpose, $\mu$ was lowered in 0.01 steps, where the respective $\Lambda$ is calculated using Eq. (3) until $G_{\text {inc }}-G \leq 0.001$. When this condition is met, $N_{0}$ is recalculated from Eq. (4).

For the incomplete gamma fit, the adjustment described above was needed in $64 \%$ of the data used here. In the other cases, the ratios $G$ and $G_{\text {inc }}$ were similar and resulted in the same gamma parameters. For the $64 \%$ of the dataset, median relative differences in $\log \left(N_{0}\right), \mu$, and $\Lambda$ ranged from 10 to $20 \%$ towards higher $N_{0}$ and lower $\mu$ and $\Lambda$. However, regardless of their different values, the relation among the gamma parameters remains unchanged in the incomplete fit because they are based on the same underlying equations. As will be shown later, the main interest of this study is in the relation among the gamma parameters and not in their values themselves. Therefore, we will focus on the complete gamma, noting that the results can be slightly shifted if truncation were to be considered.

The DSD bulk properties, such as droplet number concentration $\left(N_{\mathrm{d}}\right)$, LWC, effective droplet diameter $\left(D_{\text {eff }}\right)$, and relative dispersion $(\varepsilon)$, can be derived from the gamma parameters $N_{0}, \mu$, and $\Lambda$ by taking into account the complete gamma function integral properties. In the units considered here, the equations are given by

$$
\begin{aligned}
& N_{\mathrm{d}}=\int_{0}^{\infty} N(D) d D=N_{0} \frac{\Gamma(\mu+1)}{\Lambda^{\mu+1}} \\
& \mathrm{LWC}=10^{-9} \frac{\pi}{6} \rho_{\mathrm{w}} \int_{0}^{\infty} N(D) D^{3} d D=10^{-9} \frac{\pi}{6} \rho_{\mathrm{W}} N_{0} \frac{\Gamma(\mu+4)}{\Lambda^{\mu+4}} \\
& D_{\mathrm{eff}}=\frac{\int_{0}^{\infty} N(D) D^{3} d D}{\int_{0}^{\infty} N(D) D^{2} d D}=\frac{\mu+3}{\Lambda} \\
& \varepsilon=\frac{\sigma}{D_{\mathrm{g}}}=\frac{1}{\sqrt{\mu+1}},
\end{aligned}
$$

where $\rho_{\mathrm{w}}=1000 \mathrm{~g} \mathrm{~m}^{-3}$ represents the density of liquid water and $\sigma$ and $D_{\mathrm{g}}$ are the DSD standard deviation and mean geometric diameter, respectively. $N_{\mathrm{d}}$, LWC, and $D_{\text {eff }}$ are given in per cubic centimeter, gram per cubic meter, and micrometer, respectively. Given the choice of the conserved moments, they exactly match the respective characteristics of the observed DSDs. The parameter $\varepsilon$ is described in detail in Tas et al. (2015). The relative dispersion of the gamma DSD may differ from the observations, given the differences between the parameterized and observed DSDs. However, our measurements show that the gamma and observed $\varepsilon$ values are closely related by $\varepsilon_{\text {Gamma }}=0.95 \varepsilon_{\text {Observed }}\left(R^{2}=0.93\right)$, showing that the gamma DSDs are slightly narrower on average. We focus on $\varepsilon$ as obtained using the gamma parameters and do not use subscripts.

Cloud hydrometeor sphericity was analyzed with the NIXE-CAPS probe (New Ice eXpEriment - Cloud and Aerosol Particle Spectrometer; Luebke et al., 2016; Costa et al., 2017). NIXE-CAPS also contains two instruments, a CIPgs as the CCP and the CAS-Depol for particle measurements in the size range 0.6 to $50 \mu \mathrm{m}$. The sizing principle of CAS-Depol is similar to the CDP; the difference is the particle probing: while CAS-Depol has an inlet tube (optimized with respect to shattering), CDP is equipped with an open path inlet. In addition to the sizing, CAS-Depol is equipped with a detector to discriminate between spherical and aspherical particles by measuring the change of the polarized components of the incident light. Spherical particles do not strongly alter the polarization state, in contrast to nonspherical ice crystals. The cloud particle phase of the whole cloud particle size spectrum was analyzed from the combina- 
tion of phase determination in the size ranges $<50 \mu \mathrm{m}$ (from the CAS-Depol polarization signal) and $>50 \mu \mathrm{m}$ (from visual inspection of the CIPgs images) (for details, see Costa et al., 2017). Here, the phase states are defined as follows: "Sph (liquid)" stands for many only spherical $(D<50 \mu \mathrm{m})$ and predominantly spherical $(D>50 \mu \mathrm{m})$ hydrometeors, "Asph small (mixed phase)" for many predominantly spherical $(D<50 \mu \mathrm{m})$ and only aspherical $(D>50 \mu \mathrm{m})$ hydrometeors, "Asph large (ice)" for only very few aspherical $(D<50 \mu \mathrm{m})$ and only aspherical $(D>50 \mu \mathrm{m})$ hydrometeors. The NIXECAPS classification is a separate analysis and will not be considered as a filter to apply the gamma fits to the CDP measurements. The CDP data fits are primarily focused on the warm phase and the transition to the mixed layer, where liquid droplets predominate.

Meteorological conditions, including threedimensional (3-D) winds, were obtained with the Basic HALO Measurement and Sensor System (BAHAMAS) located at the nose of the aircraft (Wendisch et al., 2016). The wind components were calibrated according to Mallaun et al. (2015), with an uncertainty of 0.2 and $0.3 \mathrm{~m} \mathrm{~s}^{-1}$ for the horizontal and vertical directions, respectively. All probes were synchronized with BAHAMAS and operated at a frequency of $1 \mathrm{~Hz}$. All HALO instruments are listed in Wendisch et al. (2016).

\subsection{Introducing the gamma phase space}

The gamma fit parameters can be plotted in a 3-D subspace where each parameter $\left(N_{0}, \mu\right.$, and $\left.\Lambda\right)$ represents one dimension. Each point in this 3-D gamma phase space is defined by one $\left(N_{0}, \mu\right.$, and $\left.\Lambda\right)$ triplet and thus represents one fitted DSD. This space includes all possible combinations of gamma parameters of the theoretical variability in the DSDs.

The 3-D gamma phase space is illustrated in Fig. 3. There are two points in this figure defined by two location vectors $\boldsymbol{P}_{1}$ and $\boldsymbol{P}_{2}$, each one representing a fit to a specific DSD (see the insert in the left side of Fig. 3 ) at different times $\left(t_{1}\right.$ and $t_{2}$ for $t_{2}>t_{1}$ ). If we consider that $\boldsymbol{P}_{1}$ and $\boldsymbol{P}_{2}$ represent the same population of droplets evolving in time (i.e., a Lagrangian case), we can link the two points by a displacement vector $\boldsymbol{P}=\boldsymbol{P}_{2}-\boldsymbol{P}_{1}$, which can be associated with a pseudoforce $\boldsymbol{F}$ (blue arrow in Fig. 3). We use the term pseudo-force in order to illustrate that the growth processes produce displacements in the phase space. Alternatively, displacements in the phase space can also be understood as phase state transitions, in which case each phase-state is related to a DSD. The pseudo-force $\boldsymbol{F}$ can be decomposed into two components, one related to condensational growth and the other to the collision-coalescence (collection) process. The respective pseudo-forces are illustrated as $\boldsymbol{F}_{\mathrm{cd}}$ and $\boldsymbol{F}_{\mathrm{cl}}$ in Fig. 3, respectively. This approach can be applied to multiple points, defining a trajectory through the phase space (gray dotted line). The change of the DSD results in modified gamma parameters, which determine the trajectory through the gamma

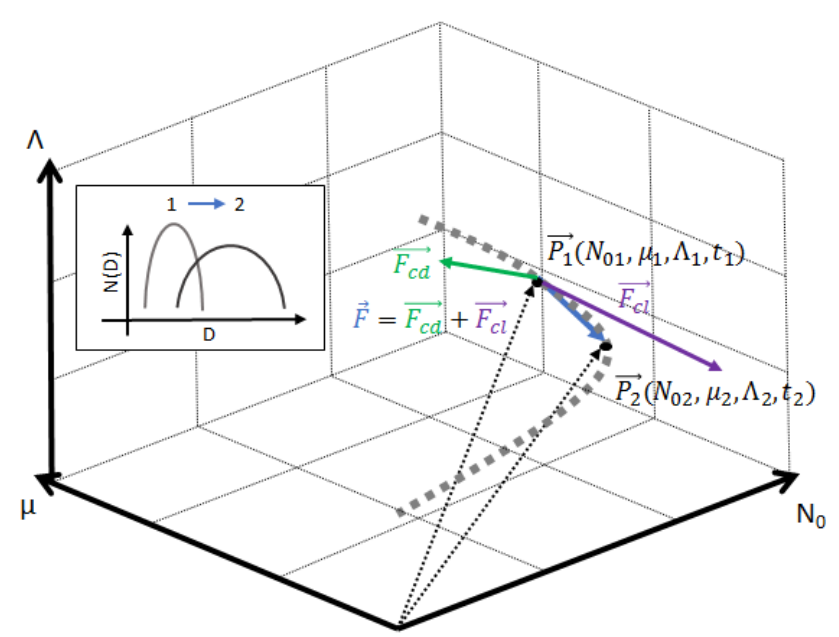

Figure 3. Conceptual drawing of the properties of the gamma phase space in the warm layer of the clouds. The dotted gray line represents one trajectory through the phase space, representing the DSD evolution. $P_{1}$ is one DSD that grows by condensation and collision-coalescence to reach $P_{2}$. The displacement represented by the pseudo-force $\boldsymbol{F}$ is decomposed into two components $-\boldsymbol{F}_{\text {cd }}$ (condensational pseudo-force) and $\boldsymbol{F}_{\mathrm{cl}}$ (collisional pseudo-force). Also shown are the two DSDs representative of points $P_{1}$ and $P_{2}$.

phase space. The direction and speed of the displacements forming the trajectory are determined by the direction and intensity of the underlying physical processes that modify the DSD (condensation and collection). These pseudo-forces are defined by properties such as the initial DSD, CCN, updraft speed, and supersaturation. Of course, this generalization considers only condensation and collision-coalescence. The pseudo-forces can be represented with more sophistication in models, including the several processes involved in DSD changes, such as evaporation, turbulence, melting from the layer above, breakup, sedimentation, etc. Therefore, these two processes can be replaced by a number of pseudo-forces as a function of the level of sophistication of the model. We should remember that this approach does not consider contributions from other levels because advection is not directly addressed. To describe the whole process of DSD evolution during the entire cloud life cycle, the contribution from other layers should be considered.

The direction of the $\boldsymbol{F}_{\mathrm{cd}}$ pseudo-force in Fig. 3 represents the transition of the DSD during the condensation process, which favors high values of $\mu$ and slightly increasing $\Lambda$. This induces both the narrowing of and a slight increase in the effective droplet diameter (see equations in Sect. 2.2) of the DSD, which is expected from conventional condensation growth theory. Because of the DSD narrowing, the intercept parameter $\left(N_{0}\right)$ is also reduced. Condensational growth may cause a broadening of the DSD in specific situations such as at the cloud base of polluted systems. However, this is an exception and most of the time con- 

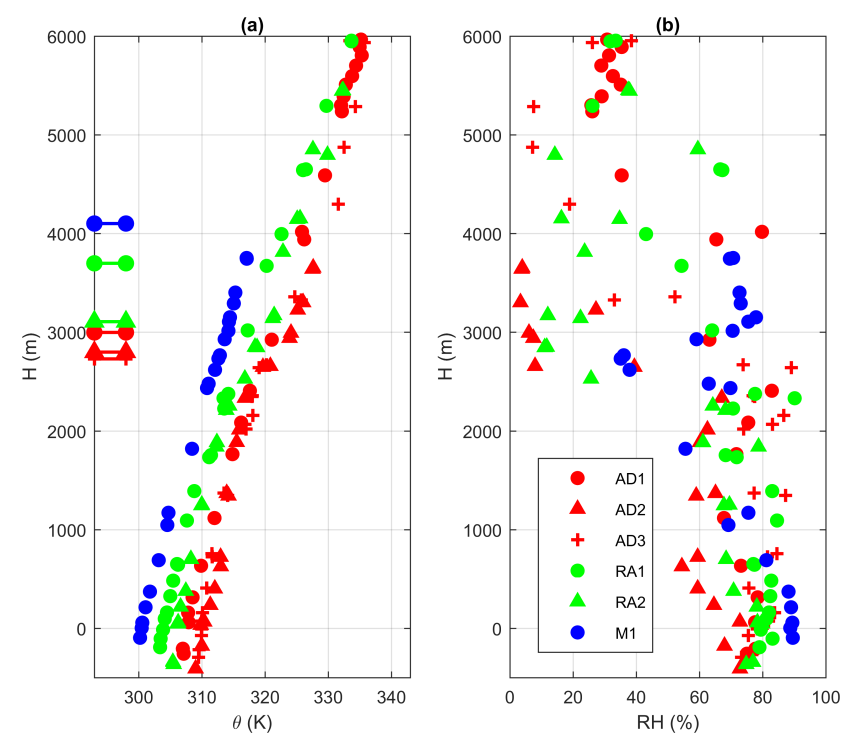

Figure 4. Average vertical profiles of potential temperature (a) and relative humidity (b) for flights over the Atlantic coast, remote Amazon, and arc of deforestation. The markers in the left vertical axis in (a) represent the altitude of the $0{ }^{\circ} \mathrm{C}$ isotherm for the different flights. Altitudes are relative to cloud base $(H$, negative values are below clouds). $\theta$ and $\mathrm{RH}$ are calculated as averages of level flight legs outside clouds.

densational growth leads to DSD narrowing. The collisioncoalescence pseudo-force acts in a significantly different way in the phase space. From theory and precise numerical simulations that solve the stochastic collection equation, it is known that this process leads to DSD broadening (given the collection of small droplets and breakup of bigger ones) and faster droplet growth in size (compared to condensation). In the gamma phase space, it should be reflected in lower values of $\Lambda$ and $\mu$, the former decreasing at a faster pace. The intercept parameter $N_{0}$ can remain relatively constant or increase because the effects of increased mean diameter and DSD broadening balance each other. If $N_{0}$ remains constant, lower values of $\Lambda$ and $\mu$ result in reduced droplet number concentration, which is consistent with theory (see Fig. 7).

To confirm the overall directions of the pseudo-forces and the characteristics of the gamma phase space, we performed some calculations with the Lagrangian model described in Feingold et al. (1999) - see their Section 3c and references therein. Basically, the model solves CCN activation (only at cloud base), condensation and collision-coalescence growth, and the effects of giant CCN on the DSDs (the latter process was turned off in our runs). The DSDs are sorted into 35 mass-doubling bins from $\sim 3 \mu \mathrm{m}$ to $\sim 9 \mathrm{~mm}$; thus, the condensation and collision-coalescence processes are not parameterized as in bulk approaches. The model was initialized with conditions that mimic flight RA1 (Table 1, Fig. 4). By performing two runs, one with exclusively condensational growth and the other with both growth processes, it was pos-

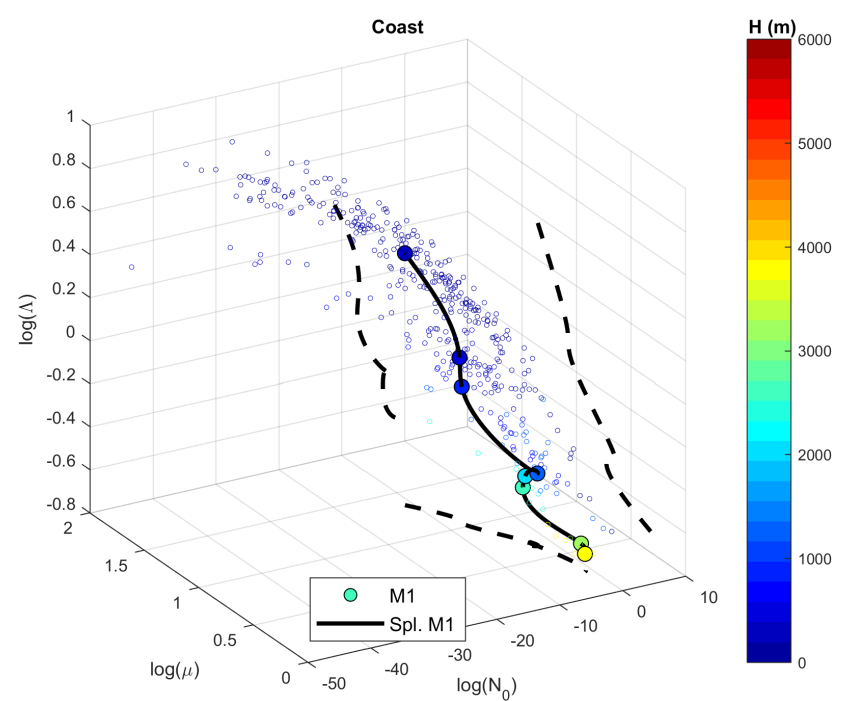

Figure 5. Gamma phase space for flight M1 over the coastal region. Small markers represent $1 \mathrm{~Hz}$ data, while bigger ones are averages for $200 \mathrm{~m}$ vertical intervals. The continuous black line represents a cubic spline fit for the averaged DSDs to illustrate its mean evolution. Altitudes are relative to cloud base $(H)$.

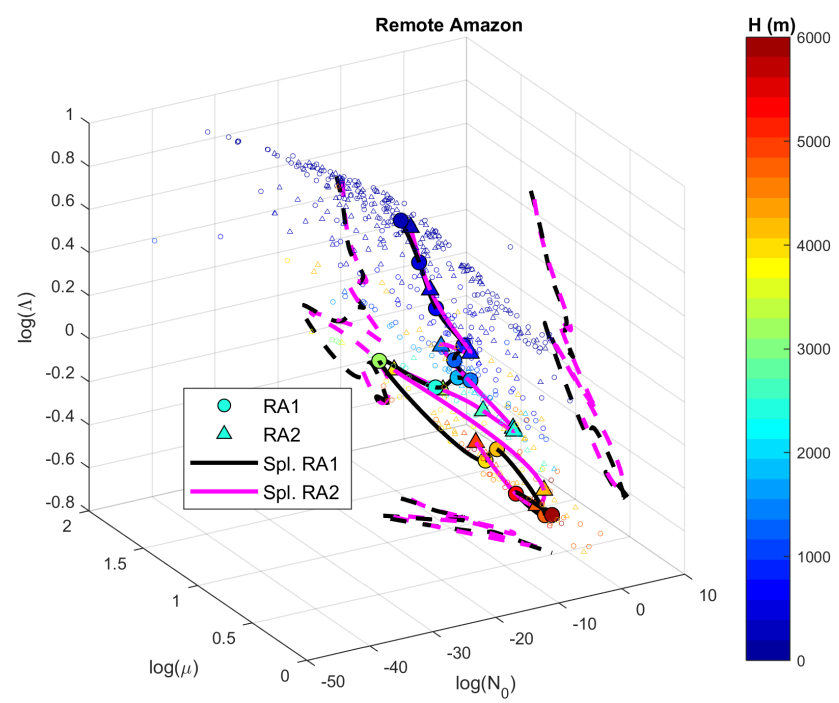

Figure 6. Similar to Fig. 5, but for flights RA1 and RA2 over the remote Amazon.

sible to isolate their effects on the DSDs. In the run with both processes active, by the time the collection was significant the droplets were big enough $\left(D_{\text {eff }}>25 \mu \mathrm{m}\right)$ to grow very slowly by condensation.

From the Lagrangian model runs it was possible to calculate the direction of the displacements caused by condensation and collision-coalescence growth in spherical coordinates. For this first introduction of the phase space, we will focus on the elevation angle $\varphi$ (from the plane $N_{0} \times \mu$ to the $\Lambda$ axis) and azimuth angle $\theta$ (calculated from the $N_{0}$ to 


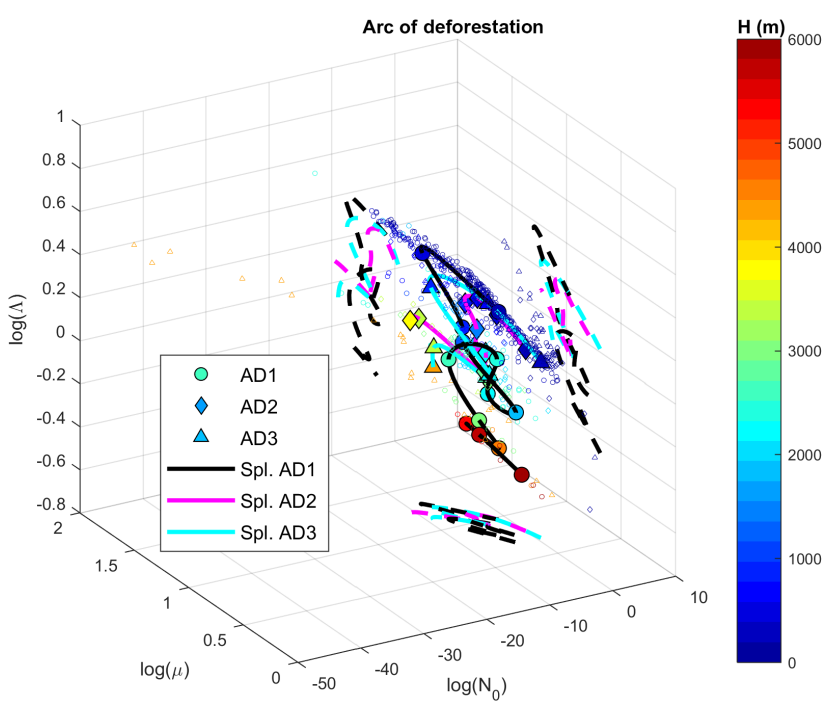

Figure 7. Similar to Fig. 5, but for flights AD1, AD2, and AD3 over the arc of deforestation.

the $\mu$ axes), when $N_{0}, \mu$, and $\Lambda$ are in logarithm (base 10) scale (as in Figs. 5-8). The angles vary depending on the relative values of $N_{0}, \mu$, and $\Lambda$, but the following numbers are provided as a first estimate. For condensational growth, $\varphi$ averaged $0.26^{\circ}$ and $\theta$ averaged $179.6^{\circ}$, while they were -4.23 and $-13.7^{\circ}$ for collision-coalescence, respectively. Note that the angles have opposite signs for the two processes and their overall direction is the same as exemplified in Fig. 3. The direction of the displacements remains consistent even when other moments are chosen to fit the gamma DSDs. For more details on the model runs, refer to the Supplement.

Note that, given the relation between the gamma parameters, the phase space is non-orthogonal and it is not trivial to mathematically represent the pseudo-forces. The mathematical treatment of such forces is beyond the scope of this paper, which intends to illustrate microphysical processes in the phase space. But this aspect should be considered in potential future implementations of this methodology in practical applications.

In Sect. 3.2, we show gamma parameters fitted to real DSD observations. As it is not feasible to follow fixed populations of droplets in a Lagrangian way with an aircraft, the evolutions we analyze in the gamma space are not strictly over time. As a compromise, we use the altitude above cloud base $(H)$ of the measurements instead of time evolution, given the conditions of the measurements and our data handling. The cloud profiling missions were planned to capture growing convective elements before reaching their mature state, which is the reason why they usually started at around 12:00 LT (local time). Additionally, we only consider DSD measurements in which updraft speed $w>0$ in order to focus on the ascending part of the growing clouds.

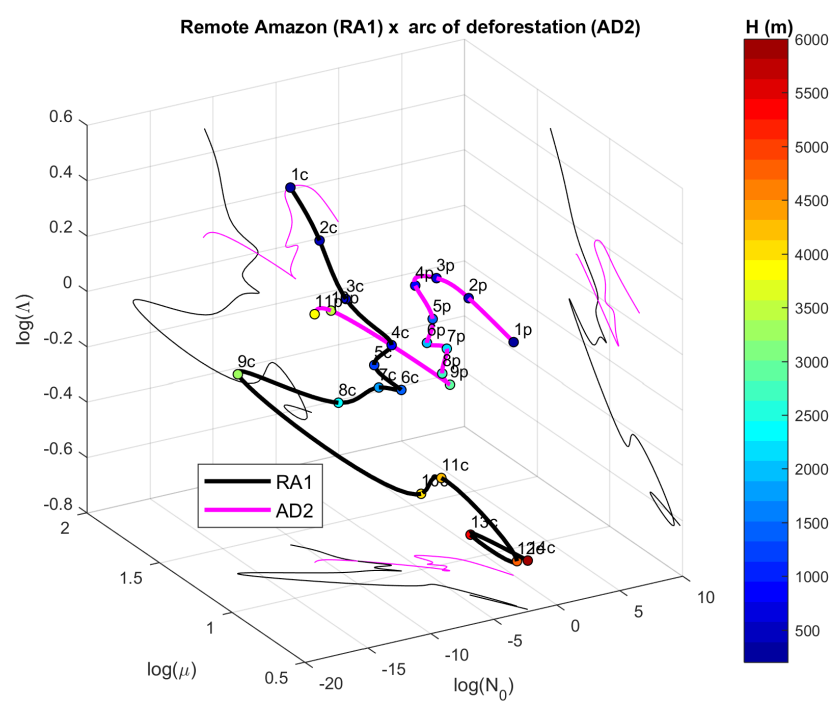

Figure 8. Observed trajectories for the clouds measured over the remote Amazon during flight RA1 (continuous line) and over the arc of deforestation during flight AD2 (dashed line). The numbers shown close to the observed trajectories start at 1 at cloud base and grow with altitude (the respective markers are colored according to altitude above cloud base, $H$ ). Their respective properties are presented in Tables 2 and 3.

Another point to take into consideration are the ellipsoids discussed in McFarquhar et al. (2015). Basically, by considering the instrument and gamma fitting uncertainties, it is possible to define volumes (with ellipsoid shapes) rather than individual points in the gamma phase space. Inside each ellipsoid, all DSDs are equally realizable and therefore the movements within it have no particular physical meaning and are statistically the same. In this study, however, we estimate that the results evolve beyond individual ellipsoids and the patterns are associated with physical processes. The results shown in the next sections will not consider the ellipsoid approach, but the points shown can be considered to be the central points of such volumes.

\section{Results}

\subsection{Aerosol and thermodynamic conditions in different Amazonian regions}

The HALO flights are classified according to the region they covered and the respective aerosol and $\mathrm{CCN}$ number concentrations (Table 1). Note the close link between region of the measurements and the aerosol concentrations. From the most pristine clouds at the coast to the most polluted cases in the arc of deforestation, there is a 10 -fold increase in $N_{\mathrm{CN}}$. Remote regions in the Amazon have aerosol particle concentrations slightly higher than over the coast, which is one of the reasons for the term "Green Ocean" used for the unpol- 
luted Amazon regions (Williams et al., 2002). Flights AD1, $\mathrm{AD} 2$, and $\mathrm{AD} 3$ present flight paths progressively shifted to the south, which are accompanied by increasing values of $N_{\mathrm{CN}}$ and $N_{\mathrm{CCN}}$. The farther away the flights take place from the forest, and consequently closer to developed regions, the higher the pollution levels.

Cloud profiles started at the end of the morning or beginning of the afternoon. The flights were specifically planned for this time period because the convective systems are usually in their developing stages at this time. The freezing level varied between 4500 and $5000 \mathrm{~m}$, while cloud base altitudes were more variable (500 to $2000 \mathrm{~m}$ ), which resulted from the regional meteorological conditions (Fig. 4), and which affects the characteristics of the cloud layers. Clouds in the arc of deforestation grow from drier air, given the diminished evapotranspiration rate, and form higher in the atmosphere. As a result, there are thinner warm layers in the polluted clouds, which reduces the time available for droplets to grow by collision-coalescence. Flight RA2 was characterized by a just slightly higher depth of the warm layer compared to the polluted clouds, partly due to the lower altitude of the freezing level. Nevertheless, cleaner clouds can present warm layers $1000 \mathrm{~m}$ thicker than clouds affected by pollution.

The vertical profile of the relative humidity $(\mathrm{RH})$ should also be taken into account when comparing clouds formed over different regions. Figure $4 \mathrm{~b}$ shows that all clouds measured formed in a surrounding environment with a RH between 60 and $90 \%$ for their lower $2500 \mathrm{~m}$ layer, with RH being higher for forested areas compared to the arc of deforestation. For $2500 \mathrm{~m}$ and above, there was a significant drying of the atmosphere for flights M1, RA2, and AD2. It is not clear if the other flights presented similar behavior given the relatively low data coverage for this layer. Regardless, surrounding dry air can significantly enhance the entrainment mixing process (Korolev et al., 2016). As pointed out by Freud et al. (2008), the mixing in Amazonian convective clouds (and also in other regions - Freud et al., 2011) tends toward the extreme inhomogeneous mixing case, in which the effective droplet diameter $D_{\text {eff }}$ presents almost no sensitivity to the entrainment. Our result largely corroborates this finding (see Fig. 11). It should be pointed out, however, that the recent studies by Korolev et al. (2016) and Pinsky et al. (2016a, b) show that homogeneous and inhomogeneous mixing can be indistinguishable depending on meteorological conditions and DSD characteristics when considering the time-dependent characteristics of the entrainment process. Mixing processes may have an impact on the shape of the DSDs measured, thus affecting displacements in the gamma phase space. The specific type of mixing responsible for it, however, is beyond the scope of this work.

\subsection{Observed trajectories in the gamma phase space}

In this study, we use the gamma phase space as a means to study DSD variability. As described in Sect. 2.3, this space is obtained when the DSD measurements are fitted to Eq. (1), and $N_{0}, \mu$, and $\Lambda$ are used as the dimensions of the 3-D subspace. In this space, each point represents one DSD. As the different DSDs were obtained close to the cloud top at the time of the cloud development, the ensemble of positions in the gamma phase space can be hypothesized as the evolution of the DSDs of a typical cloud through stages of its life cycle. The sequential connection of points (here we use cubic spline fits for illustrating purposes) can be considered as trajectories describing multiple processes responsible for the DSD variability observed. The advantage of using this space is that this variability can be readily observed and compared between different cloud life cycles with different properties. Given the relations between gamma parameters and DSD properties (Sect. 2.2), the variability in all cloud microphysical properties can also be inferred from the points in the trajectories. We limited the analysis regarding cloud DSDs and the gamma phase space to the regions in which $w>0$ in order to capture the developing parts of the growing convective elements.

Figures 5 to 7 show the gamma phase space for all profiles considered in this study, grouped by region. The coloring represents the altitude above cloud base $(H)$, with the $1 \mathrm{~Hz}$ measurements shown as small markers. Bigger markers represent averages at every $200 \mathrm{~m}$ vertical interval with available information. Curves (or trajectories) represent cubic spline fits to the averaged points. At first glance, it is possible to see stronger differences between the trajectories in the different regions, while internal variations are much weaker. Aerosol concentrations seem to be a key factor controlling warm-phase properties in the Amazon; thus, the internal similarities can be attributed to similar pollution conditions. Conversely, differences between the regions stem from the different weights of growth processes. Pristine clouds, like the ones found over the remote Amazon and the coast of the Atlantic Ocean, are characterized by faster droplet growth with altitude associated with enhanced collisional growth. In the gamma space, this is seen as diagonally tilted trajectories in Figs. 5 and 6, contrasting with the more vertical trajectories found in polluted clouds (Fig. 7).

The differences in the DSD variability in each region highlight the relation of growth processes and trajectories in the gamma phase space. From the theory described in Sect. 2.3, it is expected that collisional growth results in diagonal trajectories where the droplets get progressively bigger with DSD broadening. Pristine clouds over the coast and remote Amazon show such tilting (Figs. 5 and 6), indicating that this process is effective in these systems. The more vertically oriented trajectories of polluted clouds (Fig. 7) show that there is a different balance between condensational and collisional growth. In terms of the gamma phase space characteristics, this can be understood as weaker $\boldsymbol{F}_{\mathrm{cl}}$ as a result of smaller droplets and narrower DSDs. This highlights that the interaction between aerosols and collisional growth occurs mainly through changes in the initial DSD (i.e., $P_{1}$ in Fig. 3). For 
Table 2. Properties of the points highlighted in Fig. 8 for flight RA1. $H$ is shown as the average of each of the $200 \mathrm{~m}$ vertical bins. The adiabatic fraction is defined as the ratio between the observed and adiabatic LWC.

\begin{tabular}{lrrrcrrrrr}
\hline Point & $\begin{array}{r}H \\
(\mathrm{~m})\end{array}$ & $\begin{array}{r}N_{\mathrm{d}} \\
\left(\mathrm{cm}^{-3}\right)\end{array}$ & $\begin{array}{r}\text { LWC } \\
\left(\mathrm{g} \mathrm{m}^{-3}\right)\end{array}$ & $\varepsilon$ & $\begin{array}{r}D_{\text {eff }} \\
(\mu \mathrm{m})\end{array}$ & $\begin{array}{r}T \\
\left({ }^{\circ} \mathrm{C}\right)\end{array}$ & $\begin{array}{r}\text { UR } \\
(\%)\end{array}$ & $\begin{array}{r}w \\
\left(\mathrm{~m} \mathrm{~s}^{-1}\right)\end{array}$ & $\begin{array}{r}\text { Adiabatic } \\
\text { fraction }\end{array}$ \\
\hline $1 \mathrm{c}$ & 100 & 214 & 0.079 & 0.19 & 9.2 & 19.9 & 81 & 0.84 & 0.31 \\
$2 \mathrm{c}$ & 300 & 238 & 0.15 & 0.22 & 11.1 & 18.6 & 82 & 0.91 & 0.22 \\
$3 \mathrm{c}$ & 500 & 218 & 0.25 & 0.24 & 13.8 & 17.5 & 83 & 1.43 & 0.30 \\
$4 \mathrm{c}$ & 700 & 227 & 0.34 & 0.28 & 15.2 & 16.6 & 77 & 1.41 & 0.28 \\
$5 \mathrm{c}$ & 1100 & 245 & 0.61 & 0.27 & 18.0 & 13.6 & 85 & 1.13 & 0.31 \\
$6 \mathrm{c}$ & 1300 & 284 & 0.79 & 0.29 & 18.9 & 12.0 & 80 & 1.03 & 0.34 \\
$7 \mathrm{c}$ & 1700 & 231 & 0.79 & 0.28 & 20.1 & 10.6 & 71 & 1.49 & 0.28 \\
$8 \mathrm{c}$ & 2300 & 187 & 1.21 & 0.27 & 24.7 & 7.1 & 78 & 1.66 & 0.34 \\
$9 \mathrm{c}$ & 3100 & 233 & 1.95 & 0.22 & 26.4 & 3.5 & 64 & 2.79 & 0.47 \\
$10 \mathrm{c}$ & 3900 & 54 & 0.61 & 0.34 & 30.9 & -1.2 & 39 & 1.08 & 0.13 \\
$11 \mathrm{c}$ & 4100 & 49 & 0.31 & 0.36 & 25.6 & -1.8 & 61 & 0.31 & 0.065 \\
$12 \mathrm{c}$ & 4700 & 36 & 0.26 & 0.47 & 28.6 & -4.8 & 67 & 1.30 & 0.053 \\
$13 \mathrm{c}$ & 5300 & 39 & 0.42 & 0.40 & 31.4 & -8.1 & 26 & 2.39 & 0.083 \\
$14 \mathrm{c}$ & 5900 & 30 & 0.16 & 0.48 & 26.4 & -11.4 & 33 & 3.27 & 0.032 \\
\hline
\end{tabular}

Table 3. Properties of the points highlighted in Fig. 8 for flight AD2. $H$ is shown as the average of each of the $200 \mathrm{~m}$ vertical bins. The adiabatic fraction is defined as the ratio between the observed and adiabatic LWC.

\begin{tabular}{lrrcrrrrrc}
\hline Point & $\begin{array}{r}H \\
(\mathrm{~m})\end{array}$ & $\begin{array}{r}N_{\mathrm{d}} \\
\left(\mathrm{cm}^{-3}\right)\end{array}$ & $\begin{array}{c}\text { LWC } \\
\left(\mathrm{g} \mathrm{m}^{-3}\right)\end{array}$ & $\varepsilon$ & $\begin{array}{r}D_{\text {eff }} \\
(\mu \mathrm{m})\end{array}$ & $\begin{array}{r}T \\
\left({ }^{\circ} \mathrm{C}\right)\end{array}$ & $\begin{array}{r}\text { UR } \\
(\%)\end{array}$ & $\begin{array}{c}w \\
\left(\mathrm{~m} \mathrm{~s}^{-1}\right)\end{array}$ & $\begin{array}{c}\text { Adiabatic } \\
\text { fraction }\end{array}$ \\
\hline $\mathbf{1 p}$ & 100 & 528 & 0.11 & 0.37 & 8.4 & 16.3 & 72 & 1.17 & 0.59 \\
$2 \mathrm{p}$ & 300 & 960 & 0.27 & 0.31 & 8.8 & 15.5 & 64 & 1.02 & 0.72 \\
$3 \mathrm{p}$ & 500 & 634 & 0.21 & 0.28 & 9.2 & 14.7 & 58 & 1.28 & 0.29 \\
$4 \mathrm{p}$ & 700 & 597 & 0.29 & 0.27 & 10.4 & 12.4 & 59 & 0.57 & 0.24 \\
$5 \mathrm{p}$ & 1300 & 543 & 0.34 & 0.29 & 11.5 & 6.9 & 65 & 1.13 & 0.15 \\
$6 \mathrm{p}$ & 1900 & 1066 & 1.12 & 0.29 & 13.7 & 2.6 & 69 & 0.74 & 0.38 \\
$7 \mathrm{p}$ & 2100 & 874 & 0.75 & 0.31 & 12.8 & 2.4 & 62 & 2.89 & 0.26 \\
$8 \mathrm{p}$ & 2700 & 477 & 0.62 & 0.32 & 14.8 & 0.4 & 8 & 1.62 & 0.17 \\
$9 \mathrm{p}$ & 2900 & 1271 & 1.95 & 0.32 & 15.7 & 0.2 & 5 & 9.36 & 0.52 \\
$10 \mathrm{p}$ & 3300 & 1024 & 1.78 & 0.24 & 15.7 & -1.5 & 3 & 5.68 & 0.44 \\
$11 \mathrm{p}$ & 3700 & 137 & 0.25 & 0.24 & 16.0 & -3.6 & 4 & 0.26 & 0.06 \\
\hline
\end{tabular}

each point in the gamma phase space the collisional pseudoforces have different intensities and directions, suggesting that a vector field can be constructed. This could only be achieved with idealized model experiments, however, where the updraft speeds can also be prescribed.

Condensational growth can also be illustrated by some points in Figs. 6 and 7. Under polluted conditions, this type of growth is expected to be dominant close to cloud base where the droplets are too small to trigger collision-coalescence. In Fig. 7, this is seen in the first two or three points in the trajectories (dark blue colors), where the points evolve to higher $\mu$ values with altitude. This results in DSD narrowing and almost opposite displacement in the gamma space compared to collisional growth. This trend is shifted when the altitude at which collection processes start to become relevant is reached. Another example of condensational growth can be seen in Fig. 6 at 3000 m. At this point, which is close to the freezing level, there is a sudden increase in the updrafts (see Tables 2 and 3) and consequently increased condensation rates. The rapid increase in condensational growth, with no significant changes in collision-coalescence, tilts the trajectories to a direction similar to that observed close to cloud base in polluted systems. The displacement is closer to the horizontal direction (i.e., the plane $N_{0} \times \mu$ ), because droplets grow concomitantly by collision-coalescence in the cleaner clouds.

The magnitude of the condensational pseudo-force $\left(\boldsymbol{F}_{\mathrm{cd}}\right.$ in Fig. 3) also depends on the initial DSD characteristics $\left(P_{1}\right)$. Condensational growth rates are inversely proportional to droplet size, meaning that they get weaker higher in the cloud. The different dependences of $\boldsymbol{F}_{\mathrm{cd}}$ and $\boldsymbol{F}_{\mathrm{cl}}$ on $P_{1}$ and their balance throughout the warm-phase life cycle ultimately define the cloud trajectory in the phase space. If they can be mapped with sufficient resolution, covering different 
updraft and supersaturation conditions, trajectories may be forecast from a single DSD at cloud base and the evolving thermodynamic conditions. Aerosols are a key aspect in this regard because they significantly change the cloud base DSD in the gamma space (Figs. 5-7) and also affect cloud thermodynamics, impacting condensation rates and consequently latent heat release. Note that clouds subject to similar aerosol conditions have similarities in their trajectories represented by small variability along the trajectories of the respective flights (Figs. 6 and 7).

The $\boldsymbol{F}_{\mathrm{cd}}$ and $\boldsymbol{F}_{\mathrm{cl}}$ tabulation over the gamma space can potentially be achieved with the help of Lagrangian large-eddysimulation bin-microphysics models that precisely solve the condensation and collection equations for varying input DSDs and updraft conditions. Initial DSDs can be obtained from observations and analytical considerations. For instance, Pinsky et al. (2012) show an analytical way to obtain the maximum supersaturation (which is usually a few meters above cloud base) and the relative droplet concentration. If $D_{\text {eff }}$ behaves adiabatically (Freud et al., 2008; Freud et al., 2011) and is linearly correlated to the mean volumetric diameter (Freud and Rosenfeld, 2012), it is possible to estimate the initial DSD based on gamma DSD equations and adiabatic theory given that the aerosol population is known. The advantage of such an approach is that all DSD characteristics, most notably the shape, would be realistically represented and there would be no need for fixing or diagnosing (Thompson et al., 2004; Milbrandt and Yau, 2005; Formenton et al., 2013a, b) gamma parameters for various hydrometeor types - which works for specific applications but may be lacking the physical representation of the processes. This study focuses on introducing the gamma phase space and its characteristics, and further work is needed if new parameterizations are to be developed.

\subsection{Contrasts between clean and polluted trajectories}

In this section, we focus on flights RA1 and AD2 in order to study the differences between natural and human-affected clouds in the gamma space. Figure 8 shows the trajectories of the clouds measured during these flights, where the points related to the averaged DSDs are numbered and the corresponding properties are shown in Tables 2 and 3. The numbers start at 1 close to cloud base and grow with altitude ("p" stands for polluted, while "c" is for clean). Also presented in Tables 2 and 3 are the adiabatic fractions that correspond to the ratio between the observed and adiabatic LWC. Some observed DSDs and their corresponding gamma DSDs are shown in Fig. 9, highlighting different growth processes.

It is clear from Fig. 8 that clean and polluted clouds cover different regions of the gamma phase space. Nevertheless, it is possible to see that the trajectories can evolve almost in parallel depending on the dominant growth process. Polluted clouds have wider DSDs at cloud base because of the tail to lower diameters (Fig. 9), which brings down the value
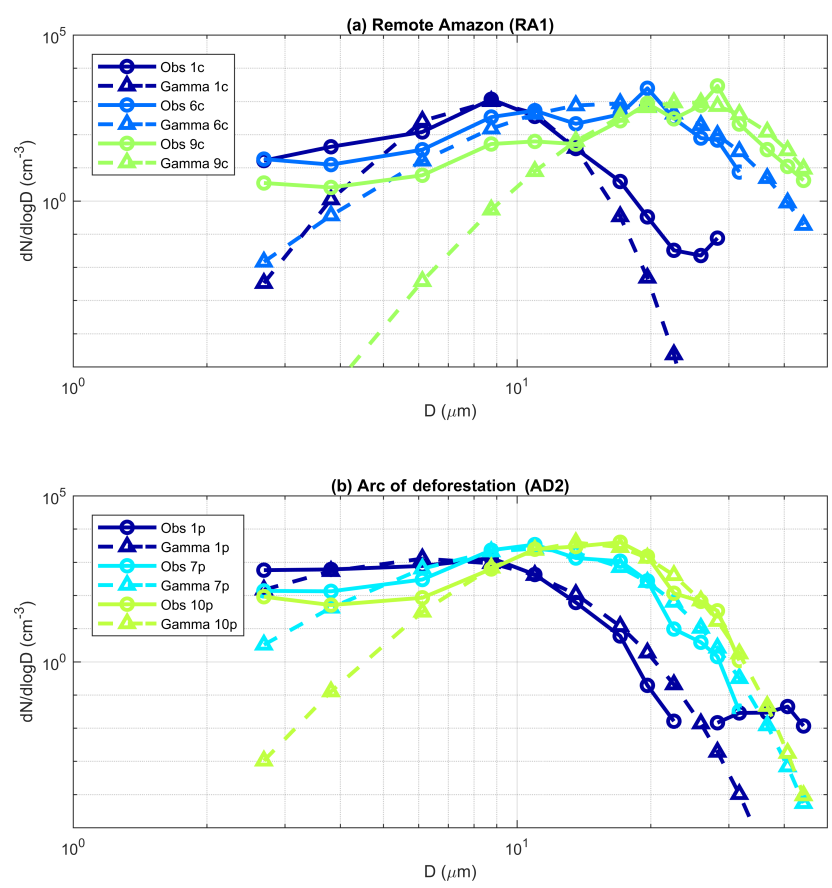

Figure 9. Averaged DSDs and their respective gamma fittings for some points in the trajectories of clouds measured over (a) the remote Amazon (flight RA1) and (b) the arc of deforestation (flight AD2).

of $\mu$ (see Eq. 9). Given the lower droplet size (Table 3), condensation is efficient and the trajectories evolve in the overall direction of $\boldsymbol{F}_{\mathrm{cd}}$ illustrated in Fig. 3. From points $1 \mathrm{p}$ to $2 \mathrm{p}, N_{\mathrm{d}}$ and LWC are approximately doubled. Condensational growth seems to be the dominant growth process in the polluted clouds up to the point $3 \mathrm{p}$, corresponding to a cloud depth of $600 \mathrm{~m}$. A similar layer does not exist in cleaner clouds, where there are enough big droplets to readily activate the collision-coalescence growth. Collisional growth dominates the DSD shape evolution between points $1 \mathrm{c}$ and $6 \mathrm{c}$ for flight RA1 and between $4 p$ and $7 p$ for AD2. Note that the trajectories are almost parallel in this region. Condensation is still active in this period given the increasing LWC, but collision-coalescence has a comparatively bigger impact on the overall DSD shape. Both sections of the trajectories represent $1400 \mathrm{~m}$ thick layers, but droplet growth and DSD broadening is more efficient in the cleaner clouds (Fig. 9). This explains the pronounced tilting of its trajectory, consistent with a stronger $\boldsymbol{F}_{\mathrm{cl}}$ pseudo-force.

Eventually, the trajectories reach a point close to the $0{ }^{\circ} \mathrm{C}$ isotherm where the updrafts are enhanced given the continued latent heat release. This $w$-enhanced layer can be several hundred meters thick and culminates in narrower DSDs. This is exemplified between points $7 \mathrm{c}$ and $9 \mathrm{c}$ and between $8 \mathrm{p}$ and 10p. Although droplets still grow by collisioncoalescence, the enhanced updrafts increase condensational growth sufficiently to produce observable effects on the 
DSDs. Both trajectories evolve in the condensational growth direction, but with slightly different tilting. The tilting is less pronounced in the cleaner clouds given the stronger $\boldsymbol{F}_{\mathrm{cl}} \mathrm{com}-$ ponent. The way in which the DSDs evolve in this region is important for the mixed-phase initiation, given that both primary and secondary ice generation depend on the characteristics of the liquid droplets. The different properties of the polluted and clean DSDs (see Tables 2 and 3, Figs. 8 and 9) indicate that ice formation may follow distinct pathways.

Previous studies suggest that droplets bigger than $23 \mu \mathrm{m}$ at concentrations higher than $1 \mathrm{~cm}^{-3}$ favor secondary ice generation, which was identified as the main mechanism for cloud glaciation (Mossop, 1978; Saunders and Hosseini, 2001; Heymsfield and Willis, 2014; Lawson et al., 2015). In order to visualize these conditions in the gamma phase space, it is interesting to consider constant $N_{\mathrm{d}}$ surfaces. These surfaces are defined when $N_{\mathrm{d}}$ is fixed in Eq. (6), resulting in a relation of the form $\Lambda=f\left(N_{0} \mu\right)$ when inverted. Examples are shown in Fig. 10, where $N_{\mathrm{d}}=\{10,100,1000\} \mathrm{cm}^{-3}$ (axes are rotated for clarity). The surfaces are evidently parallel and are stacked in relatively close proximity (on the scale used here). The trajectories evolve through the surfaces depending on their $N_{\mathrm{d}}$, where polluted clouds tend toward higher droplet concentration (i.e., closer to the red surface). These surfaces can be used to delimit specific regions of interest. Additionally, further DSD properties can be analyzed along these surfaces. Figure 10 highlights the region of $23 \mu \mathrm{m}<D_{\text {eff }}<50 \mu \mathrm{m}$ with black lines along the surface of $N_{\mathrm{d}}=10 \mathrm{~cm}^{-3}$. The purple ellipse represents an estimate of the size of the ellipsoids introduced by McFarquhar et al. (2015). For the calculation of the ellipse, we considered that the $10 \%$ error in the CDP measurements translates to $10 \%$ error in $N_{\mathrm{d}}, D_{\text {eff }}$, and $\varepsilon$. Under those conditions, the size of the ellipsoids can be represented by the purple ellipse in Fig. 10. Note that its dimension in the normal direction from the $N_{\mathrm{d}}$ surfaces is very small (1/100 of the distance between the surfaces shown); that is why we only show an ellipse rather than an ellipsoid. This simple estimate is meant to find the order of magnitude of the ellipsoids of McFarquhar et al. (2015) and it shows that the trajectories are not just random displacement inside one ellipsoid (the trajectories evolve beyond them).

Regarding cloud DSDs (drizzle droplets are not analyzed here, although they also contribute to ice formation), the region delimited by the black lines for the different surfaces of constant $N_{\mathrm{d}}$ can be interpreted as the most favorable for secondary ice generation, thus indicating a quick glaciation process. Note that the trajectory of the cleaner clouds enters this region while in the $w$-enhanced layer mentioned previously, which corresponds to the transition to temperatures below $0^{\circ} \mathrm{C}$. Polluted clouds are able to produce high droplet number concentrations, but their smaller droplet size means that they are out of the delimited region. More details about the transition to the mixed phase are given in the next section.

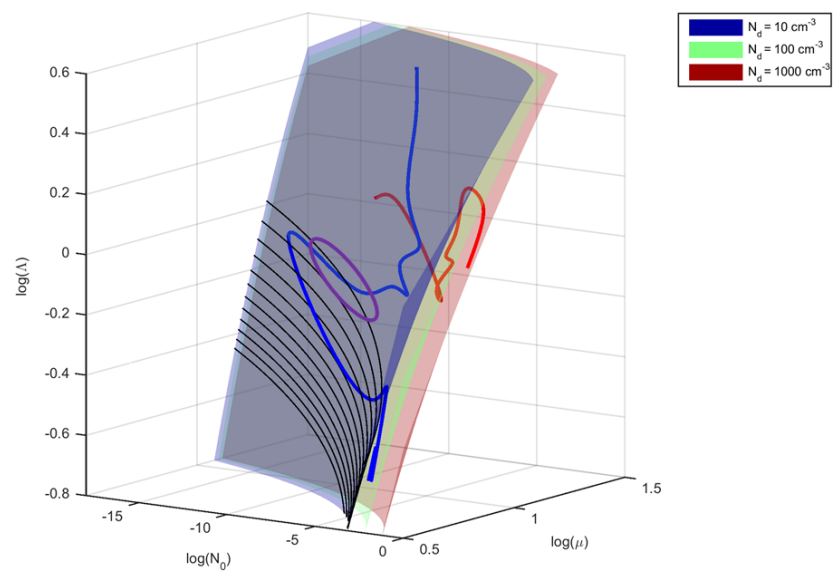

Figure 10. Surfaces of constant $N_{\mathrm{d}}$ as calculated by the inversion of Eq. (6). The trajectories for the clouds measured during flights RA1 (blue) and AD2 (red) are also shown. Note that the axes are rotated for clarity. The purple ellipse represents an estimation of the size of the ellipsoids introduced by McFarquhar et al. (2015) - see text for more details.

The observation of constant $N_{\mathrm{d}}$ surfaces poses an interesting question for parameterizations. In existing two-moment schemes, both $N_{\mathrm{d}}$ and LWC are predicted. For each pair of such properties, it is possible to define two surfaces (with constant $N_{\mathrm{d}}$ and LWC) based on Eqs. (6) and (7). These surfaces intersect, defining a curve where both properties are conserved. In this curve, the mean volumetric diameter (proportional to the ratio between LWC and $N_{\mathrm{d}}$ ) is also constant. Based on the limited information provided by the model (only two moments for three gamma parameters), this curve represents the infinite DSD solutions for the undetermined equation system. A good parameterization scheme should be able to choose one of the DSDs that best fits observations. Given the undetermined equation system, other considerations have to be made.

One parameter that varies along the infinite DSD solution curve is the relative dispersion $\varepsilon$. If $\varepsilon$ can be constrained in the model, it should be possible to obtain the full gamma DSD - which is the point in the intersection curve that presents the given $\varepsilon$. The advantage of relying on $\varepsilon$ is that it has low variability between clean and polluted clouds and its average is almost constant with altitude. Tas et al. (2015) studied the relative dispersion parameter in detail, noting that averaged values for $\varepsilon$ were independent of $N_{\mathrm{d}}$, LWC, or height, but its variability is significantly lower for the most adiabatic portions of the cloud (notably its updraft core). For precise parameterizations, $\varepsilon$ variability should be taken into account in regions with relatively low $N_{\mathrm{d}}$ and LWC, but averaged values may be considered for the updraft cores. Our observations show that $\varepsilon$ is slightly higher in polluted Amazonian clouds compared to the ones measured over remote regions mainly because of their reduced droplet size (Tables 2 
and 3). This can be considered to produce slight corrections to $\varepsilon$ based on $\mathrm{CCN}$ number concentrations.

\subsection{Observations of the mixed-phase formation}

The gamma phase space provides an insightful way to study the formation of the mixed phase by providing the history of the warm-phase development as a trajectory. Liquid cloud droplet properties are important for the glaciation process because they determine the probability of contacting INPs and the conditions for secondary generation. As shown in the previous sections, different aerosol and thermodynamic conditions alter warm-phase characteristics and can thus impact the early formation of ice in the clouds.

Figure 11 shows vertical profiles of $N_{\mathrm{d}}, \mathrm{LWC}, D_{\text {eff }}$, and $\varepsilon$ for clouds subject to background and polluted conditions (flights RA1 and AD2, respectively). It shows the different microphysical properties $(1 \mathrm{~Hz})$ of the clouds associated with the trajectories presented in Figs. 8 to $10(w>0)$. It shows that droplet concentrations are much higher in polluted clouds, which are not depleted with altitude as much as cleaner clouds (Fig. 11a and b). The lower effective diameter for clouds over the arc of deforestation may contribute to enhanced evaporation, leading to lower adiabatic fractions. As commented in the previous section, $\varepsilon$ shows small variations between the flights and does not change much with altitude.

The properties of the DSDs around the $0{ }^{\circ} \mathrm{C}$ level in Fig. 11 are a significant feature regarding the mixed-phase formation. Note that cleaner clouds have a sudden change in behavior right above the freezing level. At this point, there is a fast decrease in LWC, with higher variability in both $D_{\text {eff }}$ and $\varepsilon$. This suggests that ice processes have been triggered, disrupting the smooth evolution observed in the warm phase. In polluted clouds, this transition takes place at considerably different DSD properties. Averaged $N_{\mathrm{d}}$ reaches values above $1000 \mathrm{~cm}^{-3}$ (compared to $50 \mathrm{~cm}^{-3}$ in cleaner clouds) with very strong updrafts, bringing LWC closer to adiabaticity. However, no significant variability was observed for $D_{\text {eff }}$, suggesting that most of the water is still in a condensed state.

In order to further detail the characteristics of the hydrometeors in the transition from warm to mixed phase, we analyzed the sphericity criteria obtained with the NIXE-CAPS probe (Costa et al., 2017). The methodology developed by Costa et al. (2017) indicates whether each individual $1 \mathrm{~Hz}$ measurement contained some aspherical hydrometeors or not. This criterion can be used to indicate whether the hydrometeors are liquid (spherical), mixed (spherical and aspherical), or frozen (aspherical). By combining all measurements for clouds over the remote Amazon (RA1 and RA2) and the arc of deforestation (AD1, AD2, and AD3), we obtained the results shown in Fig. 12.

The classifications shown in Fig. 12 separate the volumes probed as containing only spherical hydrometeors ( $\mathrm{Sph}$ (liquid)) or if there are also aspherical particles too. In that case, the data are further divided into containing both
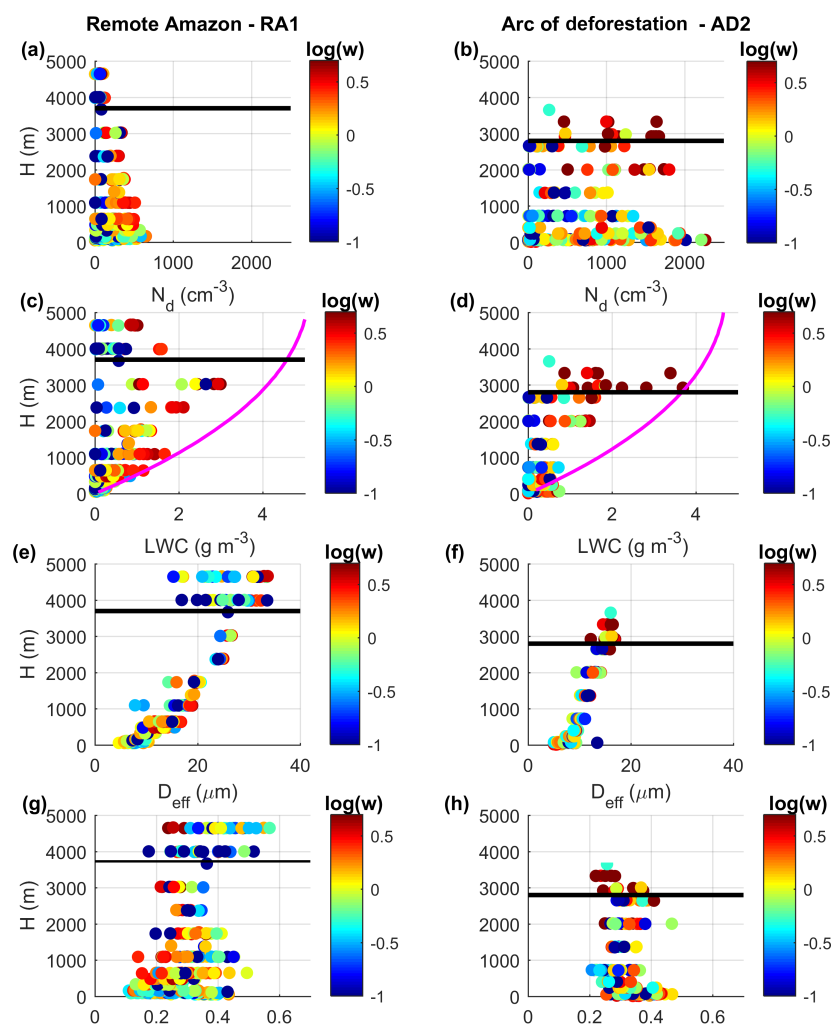

Figure 11. Vertical profiles of the $1 \mathrm{~Hz}$ measurements of $N_{\mathrm{d}}$, LWC, $D_{\text {eff }}$, and $\varepsilon$ for background clouds over the remote Amazon (a, $\mathbf{c}, \mathbf{e}, \mathbf{g})$ and polluted clouds over the arc of deforestation (b, d, f, h). Updraft speeds are colored in log scale, corresponding to $0.1 \leq w \leq 5 \mathrm{~m} \mathrm{~s}^{-1}$. Horizontal black lines mark the $0^{\circ} \mathrm{C}$ level. Magenta curves in (c) and (d) are the adiabatic water content profiles. $H$ is relative to cloud base altitude.

small $(D<50 \mu \mathrm{m})$ spherical and large aspherical particles $(D>50 \mu \mathrm{m})$ - Asph small (mixed phase) - or if there are only large $(D>50 \mu \mathrm{m})$ aspherical particles - Asph large (ice). It is possible to observe that close to cloud base most of the hydrometeors were detected as spherical for both regions, which is expected given that it is the warmest layer of the cloud. However, higher in the clouds the distribution of the classifications becomes different. The number of measurements with aspherical particles increases relatively fast for the cleaner clouds, being higher than $90 \%$ at the layer around $0{ }^{\circ} \mathrm{C}$. For polluted clouds, however, almost half of the measurements contained exclusively spherical hydrometeors at this level. Exclusively spherical hydrometeors persisted with a frequency of $\sim 20 \%$ down to temperatures of $-15^{\circ} \mathrm{C}$. This is in line with previous studies that found supercooled droplets high into continental convective systems (Rosenfeld and Woodley, 2000; Rosenfeld et al., 2008). Our results show that the persistence of supercooled droplets in Amazonian clouds is more likely under polluted conditions. 


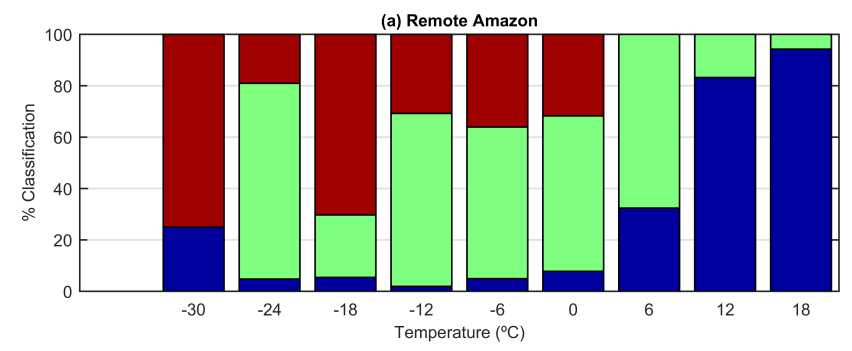

\section{Concluding remarks}

Despite being widely adopted in many modeling and remote sensing applications, there is almost no study analyzing the evolution of cloud droplet size distributions in gamma phase space. Here, we introduce this visualization, defined by the intercept, shape, and curvature of the gamma curve, which is parameterized by obtaining the moments of the orders zero, two, and three. We show that trajectories in the space are related to DSD evolution and are linked to microphysical processes taking place inside the cloud. These processes can be understood as pseudo-forces in the phase space.

Measurements over the Amazon during the ACRIDICONCHUVA and GoAmazon2014/5 campaigns show that it is possible to relate the direction of the pseudo-forces to different DSD growth processes. Cloud layers with strong updrafts and consequently relatively strong condensational growth showed that this process induces displacements in the direction of high shape and curvature parameters. This tendency is accompanied by DSD narrowing, consistent with condensational growth theory. Conversely, collision-coalescence, observable in clean clouds over the Amazon, favors displacements in roughly the opposite direction. Observed displacements in the warm phase may be interpreted as a combination of both pseudo-forces.

The gamma phase space can also be used as a diagnostic tool for cloud evolution. By studying the displacements in the warm phase, it is possible to determine regions that favor, for instance, cloud glaciation. Previous studies have identified cloud conditions that favor rapid secondary ice generation, which can be translated into the phase space. We show that clean clouds over the Amazon evolve into the region that favors secondary ice generation because of the enhanced collisional growth. Droplets in polluted clouds take much longer to grow by warm processes and they cross $0^{\circ} \mathrm{C}$ long before reaching the region favorable for glaciation. This leads to the persistence of supercooled droplets higher in the clouds, which interact with other ice processes including sublimation to produce big ice particles through the Wegener-BergeronFindeisen mechanism. In this regard, the gamma phase space approach proves to be an interesting tool to analyze the relation between warm microphysics and the evolution of the mixed phase. More studies are encouraged in that direction, especially in modeling scenarios given the difficulties in the prediction of mixed-phase processes.

We propose that the gamma space can be used to both evaluate current parameterization and steer the development of new ones. The results presented here show that different types of clouds have different trajectories through the gamma phase space. The aerosol effect seems to play a major role in the trajectories of the warm layer. The ability of current parameterizations to reproduce such aspects can be tested in the phase space, where artificially produced DSDs would be apparent. For new two-moment parameterizations, the gamma space can be used to constrain the DSD from 
the given droplet concentration and liquid water content. For each pair of these properties, the possible DSD solutions lie on a curve in the gamma space where the main differentiating factor is the distribution relative dispersion. Observations such as the ones shown here and in previous studies can be used to find the appropriate relative dispersion value to find the optimal solution. Additionally, precise bin microphysics simulations can be used in order to produce full condensational and collisional pseudo-force fields in the space. The fields would be dependent on the evolution of properties such as aerosol concentration, updraft speed, and supersaturation conditions. With such a tabulation, bulk microphysical models would only need to predict the initial DSD close to cloud base and the rest would be determined with the pseudo-force fields.

This paper shows just an initial view of potential applications of the gamma space. Future efforts are encouraged in order to test its efficiency and adequacy. Currently, we are performing bin microphysics simulations in a column model to compare different closures in bulk schemes. Additionally, we are in the process of testing the use of the gamma space in a nowcasting scenario based on dual-polarization radar retrievals.

Data availability. The data used in this study are available at https: //halo-db.pa.op.dlr.de/mission/5.

\section{The Supplement related to this article is available online at https://doi.org/10.5194/acp-17-14727-2017- supplement.}

Competing interests. The authors declare that they have no conflict of interest.

Special issue statement. This article is part of the special issues "The ACRIDICON-CHUVA campaign to study deep convective clouds and precipitation over Amazonia using the new German HALO research aircraft (ACP/AMT inter-journal SI)", "Observations and Modeling of the Green Ocean Amazon (GoAmazon2014/5) (ACP/AMT/GI/GMD inter-journal SI)", and "BACCHUS - Impact of Biogenic versus Anthropogenic emissions on Clouds and Climate: towards a Holistic UnderStanding (ACP/AMT/GMD inter-journal SI)". It is not associated with a conference.

Acknowledgements. The ACRIDICON-CHUVA campaign was supported by the Max Planck Society (MPG), the German Science Foundation (DFG Priority Program SPP 1294), the German Aerospace Center (DLR), the FAPESP (São Paulo Research Foundation) grant 2009/15235-8, and a wide range of other institutional partners. It was carried out in collaboration with the USA-Brazilian atmosphere research project GoAmazon2014/5, including numer- ous institutional partners. We also acknowledge the support from FAPESP grant 2015/14497-0. We would like to thank the Instituto Nacional de Pesquisas da Amazonia (INPA) for local logistic help prior, during, and after the campaign. Thanks also to the Brazilian Space Agency (AEB: Agencia Espacial Brasileira) responsible for the program of cooperation (CNPq license 00254/2013-9 of the Brazilian National Council for Scientific and Technological Development). The contribution of D. Rosenfeld was supported by the project BACCHUS European Commission FP7-603445. Micael A. Cecchini was funded by FAPESP grants 2014/08615-7 and 2014/21189-7. Bernadett Weinzierl would like to acknowledge funding by the Helmholtz Association (grant number VH-NG-606, AerCARE) and by the European Research Council under the European Community's Horizon 2020 research and innovation framework program/ERC grant agreement 640458 (A-LIFE). The entire ACRIDICON-CHUVA project team is gratefully acknowledged for collaboration and support. We also acknowledge the contributions from the four anonymous referees and thank Graham Feingold for providing the Lagrangian model cited in the text. The observational data used in this study can be found at http://www.halo.dlr.de/halo-db/.

Edited by: Andrew Heymsfield

Reviewed by: four anonymous referees

\section{References}

Albrecht, B. A.: Aerosols, cloud microphysics, and fractional cloudiness, Science, 245, 1227-1230, 1989.

Andreae, M. O., Rosenfeld, D., Artaxo, P., Costa, A. A., Frank, G. P., Longo, K. M., and Silva-Dias, M. A. F.: Smoking Rain Clouds over the Amazon, Science, 303, 1337-1342, 2004.

Andreae, M. O., Acevedo, O. C., Araùjo, A., Artaxo, P., Barbosa, C. G. G., Barbosa, H. M. J., Brito, J., Carbone, S., Chi, X., Cintra, B. B. L., da Silva, N. F., Dias, N. L., Dias-Júnior, C. Q., Ditas, F., Ditz, R., Godoi, A. F. L., Godoi, R. H. M., Heimann, M., Hoffmann, T., Kesselmeier, J., Könemann, T., Krüger, M. L., Lavric, J. V., Manzi, A. O., Lopes, A. P., Martins, D. L., Mikhailov, E. F., Moran-Zuloaga, D., Nelson, B. W., Nölscher, A. C., Santos Nogueira, D., Piedade, M. T. F., Pöhlker, C., Pöschl, U., Quesada, C. A., Rizzo, L. V., Ro, C.-U., Ruckteschler, N., Sá, L. D. A., de Oliveira Sá, M., Sales, C. B., dos Santos, R. M. N., Saturno, J., Schöngart, J., Sörgel, M., de Souza, C. M., de Souza, R. A. F., Su, H., Targhetta, N., Tóta, J., Trebs, I., Trumbore, S., van Eijck, A., Walter, D., Wang, Z., Weber, B., Williams, J., Winderlich, J., Wittmann, F., Wolff, S., and Yáñez-Serrano, A. M.: The Amazon Tall Tower Observatory (ATTO): overview of pilot measurements on ecosystem ecology, meteorology, trace gases, and aerosols, Atmos. Chem. Phys., 15, 10723-10776, https://doi.org/10.5194/acp-15-10723-2015, 2015.

Arakawa, A.: The cumulus parameterization problem: Past, present, and future, J. Climate, 17, 2493-2525, 2004.

Artaxo, P., Martins, J. V., Yamasoe, M. A., Procópio, A. S., Pauliquevis, T. M., Andreae, M. O., Guyon, P., Gatti, L. V., and Leal, A. M. C.: Physical and chemical properties of aerosols in the wet and dry seasons in Rondônia, Amazonia, J. Geophys. Res., 107, 8081, https://doi.org/10.1029/2001JD000666, 2002. 
Braga, R. C., Rosenfeld, D., Weigel, R., Jurkat, T., Andreae, M. O., Wendisch, M., Pöhlker, M. L., Klimach, T., Pöschl, U., Pöhlker, C., Voigt, C., Mahnke, C., Borrmann, S., Albrecht, R. I., Molleker, S., Vila, D. A., Machado, L. A. T., and Artaxo, P.: Comparing parameterized versus measured microphysical properties of tropical convective cloud bases during the ACRIDICON-CHUVA campaign, Atmos. Chem. Phys., 17, 7365-7386, https://doi.org/10.5194/acp-17-7365-2017, 2017.

Brandes, E. A., Zhang, G., and Vivekanandan, J.: An Evaluation of a Drop Distribution-Based Polarimetric Radar Rainfall Estimator, J. Appl. Meteorol., 42, 652-660, https://doi.org/10.1175/15200450(2003)042<0652:AEOADD>2.0.CO;2, 2003.

Cecchini, M. A., Machado, L. A. T., Comstock, J. M., Mei, F., Wang, J., Fan, J., Tomlinson, J. M., Schmid, B., Albrecht, R., Martin, S. T., and Artaxo, P.: Impacts of the Manaus pollution plume on the microphysical properties of Amazonian warmphase clouds in the wet season, Atmos. Chem. Phys., 16, 7029 7041, https://doi.org/10.5194/acp-16-7029-2016, 2016.

Cooper, W. A.: A possible mechanism for contact nucleation, J. Atmos. Sci., 31, 1832-1837, 1974.

Costa, A., Meyer, J., Afchine, A., Luebke, A., Günther, G., Dorsey, J. R., Gallagher, M. W., Ehrlich, A., Wendisch, M., Baumgardner, D., Wex, H., and Krämer, M.: Classification of Arctic, midlatitude and tropical clouds in the mixed-phase temperature regime, Atmos. Chem. Phys., 17, 12219-12238, https://doi.org/10.5194/acp-17-12219-2017, 2017.

Fan, J., Zhang, R., Li, G., Tao, W.-K., and Li, X.: Simulations of cumulus clouds using a spectral bin microphysics in a cloud resolving model, J. Geophys. Res., 112, D04201, https://doi.org/10.1029/2006JD007688, 2007.

Fan, J., Wang, Y., Rosenfeld, D., and Liu, X.: Review of AerosolCloud Interactions: Mechanisms, Significance and Challenges, J. Atmos. Sci., 73, 4221-4252, https://doi.org/10.1175/JAS-D-160037.1, 2016.

Feingold, G., Cotton, W. R., Kreidenweis, S. M., and Davis, J. T.: Impact of giant cloud condensation nuclei on drizzle formation in marine stratocumulus: Implications for cloud radiative properties, J. Atmos. Sci., 56, 4100-4117, 1999.

Fierro, A. O., Simpson, J., LeMone, M. A., Straka, J. M., and Smull, B. F.: On how hot towers fuel the Hadley cell: An observational and modeling study of line-organized convection in the equatorial trough from TOGA COARE, J. Atmos. Sci., 66, 2730-2746, 2009.

Fierro, A. O., Zipser, E. J., LeMone, M. A., Straka, J. M., and Simpson, J. M.: Tropical oceanic hot towers: Need they be undilute to transport energy from the boundary layer to the upper troposphere effectively? An answer based on trajectory analysis of a simulation of a TOGA COARE convective system, J. Atmos. Sci., 69, 195-213, 2012.

Fisch, G., Tota, J., Machado, L. A. T., Dias, M., Lyra, R. F. D., Nobre, C. A., Dolman, A. J., and Gash, J. H. C.: The convective boundary layer over pasture and forest in Amazonia, Theor. Appl. Climatol., 78, 47-59, 2004.

Formenton, M., Phillips, V. T. J., and Lienert, B.: A new snow microphysics parameterization applied to a cloud electrification model: Framework and preliminary results, in: 93rd AMS Annual Meeting, 6-10 January 2013, Austin, Texas, 2013a.

Formenton, M., Panegrossi, G., Casella, D., Dietrich, S., Mugnai, A., Sano, P., Di Paola, F., Betz, H.-D., Price, C., and
Yair, Y.: Using a cloud electrification model to study relationships between lightning activity and cloud microphysical structure, Nat. Hazards Earth Syst. Sci., 13, 1085-1104, https://doi.org/10.5194/nhess-13-1085-2013, 2013 b.

Freud, E. and Rosenfeld, D.:Linear relation between convective cloud drop number concentration and depth for rain initiation, J. Geophys. Res., 117, D02207, https://doi.org/10.1029/2011JD016457, 2012.

Freud, E., Rosenfeld, D., Andreae, M. O., Costa, A. A., and Artaxo, P.: Robust relations between $\mathrm{CCN}$ and the vertical evolution of cloud drop size distribution in deep convective clouds, Atmos. Chem. Phys., 8, 1661-1675, https://doi.org/10.5194/acp-8-16612008, 2008.

Freud, E., Rosenfeld, D., and Kulkarni, J. R.: Resolving both entrainment-mixing and number of activated $\mathrm{CCN}$ in deep convective clouds, Atmos. Chem. Phys., 11, 12887-12900, https://doi.org/10.5194/acp-11-12887-2011, 2011.

Gonçalves, W. A., Machado, L. A. T., and Kirstetter, P.-E.: Influence of biomass aerosol on precipitation over the Central Amazon: an observational study, Atmos. Chem. Phys., 15, 6789-6800, https://doi.org/10.5194/acp-15-6789-2015, 2015.

Hallett, J. and Mossop, S. C.: Production of secondary ice particles during the riming process, Nature, 249, 26-28, 1974.

Heiblum, R. H., Altaratz, O., Koren, I., Feingold, G., Kostinski, A. B., Khain, A. P., Ovchinnikov, M., Fredj, E., Dagan, G., Pinto, L., Yaish, R., and Chen, Q.: Characterization of cumulus cloud fields using trajectories in the center-of-gravity vs. water mass phase space: 1. Cloud tracking and phase space description, J. Geophys. Res., 121, 6336-6355, https://doi.org/10.1002/2015JD024186, 2016a.

Heiblum, R. H., Altaratz, O., Koren, I., Feingold, G., Kostinski, A. B., Khain, A. P., Ovchinnikov, M., Fredj, E., Dagan, G., Pinto, L., Yaish, R., and Chen, Q.: Characterization of cumulus cloud fields using trajectories in the center of gravity versus water mass phase space: 2 . Aerosol effects on warm convective clouds, J. Geophys. Res., 121, 6356-6373, https://doi.org/10.1002/2015JD024193, $2016 b$.

Heymsfield, A. and Willis, P.: Cloud conditions favoring secondary ice particle production in tropical maritime convection, J. Atmos. Sci., 71, 4500-4525, 2014.

Hobbs, P. V. and Rangno, A. L.: Ice particle concentrations in clouds, J. Atmos. Sci., 42, 2523-2449, 1985.

Huang, Y., Blyth, A., Brown, P., Choularton, T., Connolly, P., Gadian, A., Jones, H., Latham, J., Cui, Z., and Carslaw, K.: The development of ice in a cumulus cloud over southwest England, New J. Phys., 10, 105021, https://doi.org/10.1088/13672630/10/10/105021, 2008.

Khain, A., Rosenfeld, D., and Pokrovsky, A.: Aerosol impact on the dynamics and microphysics of convective clouds, Q. J. Roy. Meteorol. Soc., 131, 2639-2663, https://doi.org/10.1256/qj.04.62, 2005.

Khain, A. P., Beheng, K. D., Heymsfield, A., Korolev, A., Krichak, S. O., Levin, Z., Pinsky, M., Phillips, V., Prabhakaran, T., Teller, A., van den Heever, S. C., and Yano, J.-I.: Representation of microphysical processes in cloud-resolving models: spectral (bin) microphysics versus bulk parameterization, Rev. Geophys., 53, 247-322, https://doi.org/10.1002/2014RG000468, 2015.

Koren, I., Feingold, G., and Remer, L. A.: The invigoration of deep convective clouds over the Atlantic: Aerosol effect, meteorol- 
ogy or retrieval artifact?, Atmos. Chem. Phys., 10, 8855-8872, https://doi.org/10.5194/acp-10-8855-2010a, 2010.

Korolev, A.: Reconstruction of the sizes of spherical particles from their shadow images. Part I: Theoretical considerations, J. Atmos. Ocean. Tech., 24, 376-389, https://doi.org/10.1175/JTECH1980.1, 2007.

Korolev, A., Khain, A., Pinsky, M., and French, J.: Theoretical study of mixing in liquid clouds - Part 1: Classical concepts, Atmos. Chem. Phys., 16, 9235-9254, https://doi.org/10.5194/acp16-9235-2016, 2016.

Kuhn, U., Ganzeveld, L., Thielmann, A., Dindorf, T., Schebeske, G., Welling, M., Sciare, J., Roberts, G., Meixner, F. X., Kesselmeier, J., Lelieveld, J., Kolle, O., Ciccioli, P., Lloyd, J., Trentmann, J., Artaxo, P., and Andreae, M. O.: Impact of Manaus City on the Amazon Green Ocean atmosphere: ozone production, precursor sensitivity and aerosol load, Atmos. Chem. Phys., 10, 9251-9282, https://doi.org/10.5194/acp-10-9251-2010, 2010.

Lamb, D., Hallett, J., and Sax, R. I.: Mechanistic limitations to the release of latent heat during the natural and artificial glaciation of deep convective clouds, Q. J. Roy. Meteorol. Soc., 107, 935-954, 1981.

Lance, S., Brock, C. A., Rogers, D., and Gordon, J. A.: Water droplet calibration of the Cloud Droplet Probe (CDP) and inflight performance in liquid, ice and mixed-phase clouds during ARCPAC, Atmos. Meas. Tech., 3, 1683-1706, https://doi.org/10.5194/amt-3-1683-2010, 2010.

Lawson, R. P., Woods, S., and Morrison, H.: The microphysics of ice and precipitation development in tropical cumulus clouds, J. Atmos. Sci., 72, 2429-2445, https://doi.org/10.1175/JAS-D-140274.1, 2015.

Lee, S. S., Donner, L. J., Phillips, V. T. J., and Ming, Y.: Examination of aerosol effects on precipitation in deep convective clouds during the 1997 ARM summer experiment, Q. J. Roy. Meteorol. Soc., 134, 1201-1220, https://doi.org/10.1002/qj.287, 2008.

Li, Z., Niu, F., Fan, J., Liu, Y., Rosenfeld, D., and Ding, Y.: Long-term impacts of aerosols on the vertical development of clouds and precipitation, Nat. Geosci., 4, 888-894, https://doi.org/10.1038/ngeo1313, 2012.

Liu, C.: Rainfall contributions from precipitation systems with different sizes, convective intensities, and durations over the tropics and subtropics, J. Hydrometeorol., 12, 394-412, 2011.

Lohmann, U. and Hoose, C.: Sensitivity studies of different aerosol indirect effects in mixed-phase clouds, Atmos. Chem. Phys., 9, 8917-8934, https://doi.org/10.5194/acp-9-8917-2009, 2009.

Luebke, A. E., Afchine, A., Costa, A., Grooß, J.-U., Meyer, J., Rolf, C., Spelten, N., Avallone, L. M., Baumgardner, D., and Krämer, M.: The origin of midlatitude ice clouds and the resulting influence on their microphysical properties, Atmos. Chem. Phys., 16, 5793-5809, https://doi.org/10.5194/acp-16-5793-2016, 2016.

Machado, L. A. T., Silva Dias, M. A. F., Morales, C., Fisch, G., Vila, D., Albrecht, R. I., Goodman, S. J., Calheiros, A. J. P., Biscaro, T., Kummerow, C., Cohen, J., Fitzjarrald, D., Nascimento, E. L., Sakamoto, M. S., Cunningham, C., Chaboureau, J.-P., Petersen, W. A., Adams, D. K., Baldini, L., Angelis, C. F., Sapucci, L. F., Salio, P., Barbosa, H. M. J., Landulfo, E., Souza, R. A. F., Blakeslee, R. J., Bailey, J., Freitas, S., Lima, W. F. A., and Tokay, A.: The Chuva Project: How Does Convection Vary across Brazil?, B. Am. Meteorol. Soc., 95, 1365-1380, 2014.
Mallaun, C., Giez, A., and Baumann, R.: Calibration of 3-D wind measurements on a single-engine research aircraft, Atmos. Meas. Tech., 8, 3177-3196, https://doi.org/10.5194/amt-8-3177-2015, 2015.

Martin, S. T., Andreae, M. O., Artaxo, P., Baumgardner, D., Chen, Q., Goldstein, A. H., Guenther, A., Heald, C. L., Mayol-Bracero, O. L., McMurry, P. H., Pauliquevis, T., Pöschl, U., Prather, K. A., Roberts, G. C., Saleska, S. R., Silva Dias, M. A., Spracklen, D. V., Swietlicki, E., and Trebs, I.: Sources and properties of Amazonian aerosol particles, Rev. Geophys., 48, RG2002, https://doi.org/10.1029/2008RG000280, 2010.

Martin, S. T., Artaxo, P., Machado, L. A. T., Manzi, A. O., Souza, R. A. F., Schumacher, C., Wang, J., Andreae, M. O., Barbosa, H. M. J., Fan, J., Fisch, G., Goldstein, A. H., Guenther, A., Jimenez, J. L., Pöschl, U., Silva Dias, M. A., Smith, J. N., and Wendisch, M.: Introduction: Observations and modeling of the Green Ocean Amazon (GoAmazon2014/5), Atmos. Chem. Phys., 16, 47854797, https://doi.org/10.5194/acp-16-4785-2016, 2016.

McFarquhar, G. M., Hsieh, T., Freer, M., Mascio, J., and Jewett, B. F.: The characterization of ice hydrometeor gamma size distributions as volumes in $N_{0}-\lambda-\mu$ phase space: Implications for microphysical process modeling, J. Atmos. Sci., 72, 892-909, https://doi.org/10.1175/JAS-D-14-0011.1, 2015.

Milbrandt, J. A. and Yau, M. K.: A multimoment bulk microphysics parameterization. Part I: Analysis of the role of the spectral shape parameter, J. Atmos. Sci., 62, 3051-3064, 2005.

Molleker, S., Borrmann, S., Schlager, H., Luo, B., Frey, W., Klingebiel, M., Weigel, R., Ebert, M., Mitev, V., Matthey, R., Woiwode, W., Oelhaf, H., Dörnbrack, A., Stratmann, G., Grooß, J.U., Günther, G., Vogel, B., Müller, R., Krämer, M., Meyer, J., and Cairo, F.: Microphysical properties of synoptic scale polar stratospheric clouds: in situ measurements of unexpectedly large HNO3 containing particles in the Arctic vortex, Atmos. Chem. Phys., 14, 10785-10801, https://doi.org/10.5194/acp-14-107852014, 2014.

Mossop, S. C.: The influence of drop size distribution on the production of secondary ice particles during graupel growth, Q. J. Roy. Meteorol. Soc., 104, 323-330, 1978.

Pinsky, M., Khain, A., Mazin, I., and Korolev, A.: Analytical estimation of droplet concentration at cloud base, J. Geophys. Res., 117, D18211, https://doi.org/10.1029/2012JD017753, 2012.

Pinsky, M., Khain, A., Korolev, A., and Magaritz-Ronen, L.: Theoretical investigation of mixing in warm clouds - Part 2: Homogeneous mixing, Atmos. Chem. Phys., 16, 9255-9272, https://doi.org/10.5194/acp-16-9255-2016, 2016 a.

Pinsky, M., Khain, A., and Korolev, A.: Theoretical analysis of mixing in liquid clouds - Part 3: Inhomogeneous mixing, Atmos. Chem. Phys., 16, 9273-9297, https://doi.org/10.5194/acp16-9273-2016, $2016 \mathrm{~b}$.

Pöhlker, C., Wiedemann, K., Sinha, B., Shiraiwa, M., Gunthe, S., Smith, M., Su, H., Artaxo, P., Chen, Q., Cheng, Y., Elbert, W., Gilles, M. K., Kilcoyne, A. L. D., Moffet, R. C., Weigand, M., Martin, S. T., Pöschl, U., and Andreae, M. O., Biogenic potassium salt particles as seeds for secondary organic aerosol in the Amazon, Science, 337, 1075-1078, 2012.

Pöhlker, M. L., Pöhlker, C., Ditas, F., Klimach, T., Hrabe de Angelis, I., Araújo, A., Brito, J., Carbone, S., Cheng, Y., Chi, X., Ditz, R., Gunthe, S. S., Kesselmeier, J., Könemann, T., Lavrič, J. V., Martin, S. T., Mikhailov, E., Moran-Zuloaga, D., Rose, D., Sat- 
urno, J., Su, H., Thalman, R., Walter, D., Wang, J., Wolff, S., Barbosa, H. M. J., Artaxo, P., Andreae, M. O., and Pöschl, U., Longterm observations of cloud condensation nuclei in the Amazon rain forest - Part 1: Aerosol size distribution, hygroscopicity, and new model parametrizations for CCN prediction: Atmos. Chem. Phys., 16, 15709-15740, https://doi.org/10.5194/acp-16-157092016, 2016.

Pöschl, U., Martin, S. T., Sinha, B., Chen, Q., Gunthe, S. S., Huffman, J. A., Borrmann, S., Farmer, D. K., Garland, R. M., Helas, G., Jimenez, J. L., King, S. M., Manzi, A., Mikhailov, E., Pauliquevis, T., Petters, M. D., Prenni, A. J., Roldin, P., Rose, D., Schneider, J., Su, H., Zorn, S. R., Artaxo, P., and Andreae, M. O.: Rainforest aerosols as biogenic nuclei of clouds and precipitation in the Amazon, Science, 329, 1513-1516, 2010.

Prenni, A. J., Petters, M. D., Kreidenweis, S. M., Heald, C. L., Martin, S. T., Artaxo, P., Garland, R. M., Wollny, A. G., and Pöschl, U.: Relative roles of biogenic emissions and Saharan dust as ice nuclei in the Amazon Basin, Nat. Geosci., 2, 402-405, https://doi.org/10.1038/ngeo517, 2009.

Riehl, H. and Malkus, J. S.: On the heat balance in the equatorial trough zone, Geophysica, 6, 503-538, 1958.

Riehl, H. and Simpson, J. S.: On the heat balance in the equatorial trough zone, revisited, Contrib. Atmos. Phys., 52, 287-305, 1979.

Roberts, G. C. and Nenes, A.: A Continuous-Flow streamwise thermal-gradient $\mathrm{CCN}$ chamber for atmospheric measurements, Aerosol Sci. Tech., 39, 206-221, https://doi.org/10.1080/027868290913988, 2005.

Roberts, G. C., Nenes, A., Seinfeld, J. H., and Andreae, M. O.: Impact of biomass burning on cloud properties in the Amazon Basin, J. Geophys. Res., 108, 4062, https://doi.org/10.1029/2001JD000985, 2003.

Rosenfeld, D. and Woodley, W. L.: Deep convective clouds with sustained supercooled liquid water down to $-37.5^{\circ} \mathrm{C}$, Nature, 405, 440-442, https://doi.org/10.1038/35013030, 2000.

Rosenfeld, D., Lohmann, U., Raga, G. B., O’Dowd, C. D., Kulmala, M., Fuzzi, S., Reissell, A., and Andreae, M. O.: Flood or drought: How do aerosols affect precipitation?, Science, 321, 1309-1313, 2008.

Rosenfeld, D., Andreae, M. O., Asmi, A., Chin, M., de Leeuw, G., Donovan, D. P., Kahn, R., Kinne, S., Kivekäs, N., Kulmala, M., Lau, W., Schmidt, K. S., Suni, T., Wagner, T., Wild, M., and Quaas, J.: Global observations of aerosolcloudprecipitation-climate interactions, Rev. Geophys., 52, 750808, https://doi.org/10.1002/2013RG000441, 2014.

Saunders, C. P. R. and Hosseini, A. S.: A laboratory study of the effect of velocity on Hallett-Mossop ice crystal multiplication, Atmos. Res., 59-60, 3-14, 2001.

Seifert, A. and Beheng, K. D.: A two-moment cloud microphysics parameterization for mixed-phase clouds. Part 2: Maritime vs. continental deep convective storms, Meteorol. Atmos. Phys., 92, 67-82, 2006.

Sun, J., Parisa, A., Ariya, H., Leighton, G., and Yau, M. K.: Modeling study of ice formation in warm-based precipitating shallow cumulus clouds, J. Atmos. Sci., 69, 3315-3335, 2012.

Talbot, R. W., Andreae, M. O., Andreae, T. W., and Harriss, R. C., Regional aerosol chemistry of the Amazon Basin during the dry season, J. Geophys. Res., 93, 1499-1508, 1988.
Talbot, R. W., Andreae, M. O., Berresheim, H., Artaxo, P., Garstang, M., Harriss, R. C., Beecher, K. M., and Li, S. M., Aerosol chemistry during the wet season in Central Amazonia: The influence of long-range transport, J. Geophys. Res., 95, 16955-16969, 1990.

Tao, W.-K., Chen, J.-P., Li, Z., Wang, C., and Zhang, C.: Impact of aerosols on convective clouds and precipitation, Rev. Geophys., 50, RG2001, https://doi.org/10.1029/2011RG000369, 2012.

Tas, E., Teller, A., Altaratz, O., Axisa, D., Bruintjes, R., Levin, Z., and Koren, I.: The relative dispersion of cloud droplets: its robustness with respect to key cloud properties, Atmos. Chem. Phys., 15, 2009-2017, https://doi.org/10.5194/acp-152009-2015, 2015.

Thompson, G., Rasmussen, R. M., and Manning, K.: Explicit forecasts of winter precipitation using an improved bulk microphysics scheme. Part I: Description and sensitivity analysis, Mon. Weather Rev., 132, 519-542, 2004.

Twomey, S.: Pollution and the planetary albedo, Atmos. Environ., 8, 1251-1256, https://doi.org/10.1016/0004-6981(74)90004-3, 1974.

Ulbrich, C. W.: Natural variations in the analytical form of the raindrop size distribution, J. Clim. Appl. Meteorol., 22, 1764-1775, 1983.

Ulbrich, C. W.: The Effects of Drop Size Distribution Truncation on Rainfall Integral Parameters and Empirical Relations, J. Clim. Appl. Meteorol., 24, 580-590, https://doi.org/10.1175/15200450(1985)024<0580:TEODSD>2.0.CO;2, 1985.

van den Heever, S. C. and Cotton, W. R.: Urban aerosol impacts on downwind convective storms, J. Appl. Meteorol. Clim., 46, 828-850, 2007.

van den Heever, S. C., Carrió, G. G., Cotton, W. R., DeMott, P. J., and Prenni, A. J.: Impacts of nucleating aerosol on Florida storms. Part I: Mesoscale simulations, J. Atmos. Sci., 63, 1752 1775, https://doi.org/10.1175/JAS3713.1, 2006.

Vera, C., Higgins, W., Amador, J., Ambrizzi, T., Garreaud, R., Gochis, D., Gutzler, D., Lettenmaier, D., Marengo, J., Mechoso, C.R., Nogues-Paegle, J., Silva Diaz, P. L., and Zhang, C.: Towards a unified view of the American Monsoon System, J. Climate, 19, 4977-5000, 2006.

Vivekanandan, J., Zhang, G., and Brandes, E.: Polarimetric Radar Estimators Based on a Constrained Gamma Drop Size Distribution Model, J. Appl. Meteorol., 43, 217-230, https://doi.org/10.1175/15200450(2004)043<0217:PREBOA>2.0.CO;2, 2004.

Weigel, R., Spichtinger, P., Mahnke, C., Klingebiel, M., Afchine, A., Petzold, A., Krämer, M., Costa, A., Molleker, S., Reutter, P., Szakáll, M., Port, M., Grulich, L., Jurkat, T., Minikin, A., and Borrmann, S.: Thermodynamic correction of particle concentrations measured by underwing probes on fast-flying aircraft, Atmos. Meas. Tech., 9, 5135-5162, https://doi.org/10.5194/amt-95135-2016, 2016.

Wendisch, M. and Brenguier, J.-L. (Eds.): Airborne Measurements for Environmental Research: Methods and Instruments, WileyVCH Verlag GmbH \& Co. KGaA, Weinheim, Germany, 655 pp., https://doi.org/10.1002/9783527653218, 2013.

Wendisch, M., Pöschl, U., Andreae, M. O., Machado, L. A. T., Albrecht, R., Schlager, H., Rosenfeld, D., Martin, S. T., Abdelmonem, A., Afchine, A., Araújo, A., Artaxo, P., Aufmhoff, H., Barbosa, H. M. J., Borrmann, S., Braga, R., Buchholz, B., Cec- 
chini, M. A., Costa, A., Curtius, J., Dollner, M., Dorf, M., Dreiling, V., Ebert, V., Ehrlich, A., Ewald, F., Fisch, G., Fix, A., Frank, F., Fütterer, D., Heckl, C., Heidelberg, F., Hüneke, T., Jäkel, E., Järvinen, E., Jurkat, T., Kanter, S., Kästner, U., Kenntner, M., Kesselmeier, J., Klimach, T., Knecht, M., Kohl, R., Kölling, T., Krämer, M., Krüger, M., Krisna, T. C., Lavric, J. V., Longo, K., Mahnke, C., Manzi, A. O., Mayer, B., Mertes, S., Minikin, A., Molleker, S., Münch, S., Nillius, B., Pfeilsticker, K., Pöhlker, C., Roiger, A., Rose, D., Rosenow, D., Sauer, D., Schnaiter, M., Schneider, J., Schulz, C., de Souza, R. A. F., Spanu, A., Stock, P., Vila, D., Voigt, C., Walser, A., Walter, D., Weigel, R., Weinzierl, B., Werner, F., Yamasoe, M. A., Ziereis, H., Zinner, T., Zöger, M.: The ACRIDICON-CHUVA campaign: Studying tropical deep convective clouds and precipitation over Amazonia using the new German research aircraft HALO, B. Am. Meteorol. Soc., 97, 1885-1908, https://doi.org/10.1175/BAMS-D-14$00255.1,2016$.
Williams, E., Rosenfeld, D., Madden, N., Gerlach, J., Gears, N., Atkinson, L., Dunnemann, N., Frostrom, G., Antonio, M., Biazon, B., Camargo, R., Franca, H., Gomes, A., Lima, M., Machado, R., Manhaes, S., Nachtigall, L., Piva, H., Quintiliano, W., Machado, L., Artaxo, P., Roberts, G., Renno, N., Blakeslee, R., Bailey, J., Boccippio, D., Betts, A., Wolff, D., Roy, D., Halverson, J., Rickenbach, T., Fuentes, J., and Avelino, E., Contrasting convective regimes over the Amazon: Implications for cloud electrification, J. Geophys. Res., 107, 8082, https://doi.org/10.1029/2001JD000380, 2002.

Young, K. C.: The role of contact nucleation in ice phase initiation in clouds, J. Atmos. Sci., 31, 768-776, 1974.

Zhang, G., Vivekanandan, J., and Brandes, E.: A method for estimating rain rate and drop size distribution from polarimetric radar measurements, IEEE T. Geosci. Remote, 39, 830-841, 2001.

Zhou, J. and Lau, K. M.: Does a Monsoon Climate Exist over South America?, J. Climate, 11, 1020-1040, 1998. 